\title{
Motion of the Cochlear Reticular Lamina Varies Radially Across Outer-Hair-Cell Rows
}

\author{
Nam Hyun Cho ${ }^{1,2}$ and Sunil Puria ${ }^{1,2,3,{ }^{*}}$ \\ ${ }^{1}$ Department of Otolaryngology-Head and Neck Surgery, Harvard Medical School, \\ Boston, MA 02114, USA \\ 2Eaton-Peabody Laboratories, Massachusetts Eye and Ear, Boston, MA 02114, USA \\ ${ }^{3}$ Speech and Hearing Bioscience and Technology Program, Harvard University, \\ Cambridge, MA 02138, USA
}

*Corresponding Author: Email: Sunil Puria@meei.harvard.edu

Keywords: Optical Coherence Tomography (OCT), Cochlea, Organ of Corti, Cortilymph, Cochlear Mechanics 


\section{Abstract}

The basilar membrane $(\mathrm{BM})$ is connected to the reticular lamina $(\mathrm{RL})$ through three rows of Y-shaped structures consisting of an outer hair cell $(\mathrm{OHC})$ and a Deiters' cell (DC) with a phalangeal process (PhP) that forms part of the RL mosaic surface. Morphological differences in the anatomy of the Y-shaped structures across the three $\mathrm{OHC}$ rows suggest differences in motion across the rows. Here we report OoC transverse motions measured across several radial locations for the gerbil basal region corresponding to $\sim 45 \mathrm{kHz}$. Cross-sectional imaging and vibrometry measurements were made using a high-resolution (2.23 um axially in water) spectral-domain opticalcoherence-tomography (SD-OCT) system. The stimuli were pure tones $(2-63 \mathrm{kHz})$ at ear-canal sound pressure levels (SPLs) of 30-95 dB SPL in anesthetized gerbils ( $N=9)$ with healthy cochleae. We report displacements at the $R L$ regions of $\mathrm{OHC}$ rows 1-3 $\left(\mathrm{RL}_{1-3}\right)$, at the OHC-DC junctions of OHC rows 1-3 (OHC-DC-junction $\left.{ }_{1-3}\right)$, and at the arcuate zone, arcuate-pectinate junction, and pectinate zone of the $B M\left(B M_{A Z}, B_{A P J}\right.$, and $\mathrm{BM}_{\mathrm{PZ}}$, respectively). The in vivo BM displacements showed classic compressive nonlinearity and traveling-wave delays. The $R L$ gain was similar to the BM gain at low frequencies $(<20 \mathrm{kHz})$, but increased with frequency. Near the best frequency (BF), the $R L$ gain was greater than the high-level $B M$ gain by $40 \pm 5 \mathrm{~dB}$ (mean \pm std), and had greater compressive nonlinearity. $R L$ motion varied radially, and the $R L_{3}$ gain was significantly greater than that of $R_{1}$ by $10 \pm 1 \mathrm{~dB}(p<0.001)$. In contrast, the OHC-DCjunction gain varied little radially across OHCs. At low frequencies the OHC-DC-junction gain was constant across SPLs, and $14 \pm 3 \mathrm{~dB}$ greater than the BM gain. As the frequency increased, the OHC-DC-junction gain decreased to a level similar to the BM gain at $B F$. The $R L_{2,3}$ phase was advanced by $0.25-0.375$ cycles relative to the $B M$ phase at low frequencies, but the $R L_{2}, 3$ phase lead decreased as the frequency increased, became similar to the BM phase at BF, and lagged behind the BM phase by $0.25-0.5$ cycles above BF. The OHC-DC-junction phases were mostly similar to the BM phase at low frequencies, but became delayed relative to the BM as the frequency increased, typically by $0.25-0.5$ cycles near BF and by up to 1 cycle above BF. Our results show the most detailed picture of motion around the three $\mathrm{OHC}$ rows yet published, indicating that $\mathrm{RL}$ motion varied radially. Surprisingly, there was little motion difference across the three $\mathrm{OHC}$ rows in the OHC-DC-junction region, indicating that the tops of the DCs move in unison. Our data show a rich array of OoC amplitude and phase variations that are not explained by current theories. 


\section{Introduction}

The great sensitivity and frequency selectivity of mammalian hearing originates in the mechanical properties of the cochlea. Cochlear mechanical motions in response to sound are amplified using metabolic energy. The motor element of this cochlear amplification is the outer hair cell $(\mathrm{OHC})$, that can change its length at sound frequencies. Each basally-tilted $\mathrm{OHC}$, along with its attached Deiters' cell (DC) and the long apically-tilted DC phalangeal process (PhP), form a Y-shaped building block of the complex mechanical skeleton (Soons et al., 2015) occupying the space between the reticular lamina $(R L)$ and the basilar membrane $(B M)$ within the organ of Corti $(\mathrm{OoC})$. How the OHCs, acting through this skeleton of $\mathrm{Y}$-shaped structures, work to achieve cochlear amplification is not fully understood.

In the classic view of the cochlea, BM motion was considered the most important, and the motions of the rest of the $\mathrm{OoC}$ were thought to follow the BM motion (reviews: Robles and Ruggero, 2001; Guinan et al., 2012). However, recently developed optical methods have allowed motion measurements within the $\mathrm{OoC}$ of live, sensitive animals, and have revealed a much different picture. In response to sound, motions of other structures within the $\mathrm{OoC}$ are much larger than $\mathrm{BM}$ motion, and have motion responses that are amplified over a larger frequency range than the BM (e.g., Chen et al., 2011; Ramamoorthy et al., 2014; Lee et al., 2015; 2016; Ren et al., 2016; Fallah et al., 2019).

Another recent development is the realization that the phasing of the $\mathrm{OHC}$ motion required to amplify BM motion does not arise from a resonance in the tectorial membrane (TM; Dong and Olson 2013; Lee et al., 2016; Guinan, 2020), but is instead arises from an unexpected phase of the radial motion of the $R L$. The $R L$ radial-motion phase measured by Lee et al. (2016) was almost opposite to the phase expected from the $\mathrm{OoC}$ rotation resulting from $\mathrm{BM}$ motion. How such an $\mathrm{RL}$ phase might be produced is unknown. The RL surface is a mosaic comprised of the cuticular plates of the basally tilted OHCs and apically tilted PhPs, all held together by adhesion molecules (Aijaz et al., 2006; Nunes et al., 2006), and as such it is likely to bend and/or stretch. It seems possible that skeleton of $\mathrm{Y}$-shaped structures below the RL mosaic may play a role in creating the required $\mathrm{RL}$ radial-motion phase. The longitudinal and radial angles of the $\mathrm{PhP}$ branches of the $\mathrm{Y}$-shaped structures vary across the three rows of OHCs (Soons et al., 2015), and this might cause the motions to be different across the three OHC rows, but this has yet to be experimentally or computationally demonstrated.

Most past work that measured motion in the OoC has concentrated on the motion profile along the direction corresponding to the $\mathrm{OHC}$ length change due to electromotility, which is the direction in which the $\mathrm{OHC}$ force acting against the $\mathrm{BM}$ is expected to produce BM cochlear amplification (e.g., Dewey et al, 2021). Here we examine $\mathrm{OoC}$ motion at various depths along this direction, and also at different radial locations, namely at each of the three rows of OHCs. The results should help in understanding how the OoC works, and may shed light on the mechanisms by which the $\mathrm{RL}$ radial motion could achieve the correct phase for cochlear amplification. 
The location relative to the anatomy in the gerbil hook region where vibration measurements were made is shown in Figure 1a-c. At the wavelength of our optical coherence tomography (OCT) system, there were reflectivity peaks suitable for making measurements at the RL, at the bottom of each $\mathrm{OHC}$ at its junction with the $\mathrm{DC}(\mathrm{OHC}-$ DC-junction), and at the BM (Fig. 1d-g). At the RL and OHC-DC-junction points, it was often possible to see separate areas of high reflectivity that were aligned with each of the three $\mathrm{OHC}$ rows. The second-row area of high reflectivity was sometimes best seen at a slightly different longitudinal location, thus requiring a slight longitudinal offset ( 15 $\mu \mathrm{m}$ ) of the row 2 measurements relative to those of rows 1 and 3 .

\section{Motion measurements and gains}

An example of motion displacement measurements from $R L_{3}$ (the $R L$ point at the top of $\mathrm{OHC}_{3}$, the third $\mathrm{OHC}$ row), along with the corresponding ear-canal sound pressure measurements, are shown in Figure 2. Also shown is the ratio (motion/sound-pressure), which we refer to as the motion "gain." In all later figures, the motion displacement measurements are expressed in terms of their gain, which includes both a magnitude and a phase.

Figure 2 shows that as the sound level went up, the $R L_{3}$ motion grew compressively at frequencies near the best frequency (BF), but at low frequencies $(<20 \mathrm{kHz})$ it grew close to linearly (i.e., the gains stayed the same, e.g., Figs. 2c, 3d, 4a). At BF, the RL motion had more than $60 \mathrm{~dB}$ of gain relative to the motion in the dead animal (Fig. 2c). This extraordinarily high gain demonstrates that this was a sensitive preparation. Repeated measurements made at the same location indicate that the in vivo specimen was stable even after 6 hours (Fig. 2c, dotted black and solid red lines). There was little variation in phase across sound levels (the red lines all overlap), but the phase did change from living to dead (Fig. 2f, g). At low frequencies there was almost a reversal of the $\mathrm{RL}_{3}$ motion phase.

\section{Motion across the tops of the three OHC rows $\left(R L_{1-3}\right)$}

The motions in one animal at the points on the $R L$ surface corresponding to the apical surface of each of the three rows of $O H C s\left(R L_{1}, R L_{2}\right.$, and $\left.R L_{3}\right)$ are shown in Figures 3-4. The gains in the living and dead animal, along with OCT images of the anatomy from the same living animal, are shown in Figure 3. To help remove the contribution to $\mathrm{RL}$ motion of the $B M$ traveling wave, we normalized the $R L$ gain by the $\mathrm{BM}$ gain at the junction between the arcuate and pectinate zones (BM $\left.\mathrm{APJ}_{\mathrm{J}}\right)$, by averaging multiple measurements made at a high stimulus level where there was relatively little cochlear amplification (Fig. 4). Results from additional animals are shown in Supplementary Information.

The data from all three $\mathrm{RL}$ rows show similar patterns of compressive nonlinear growth near BF, linear growth at low frequencies, and phases consistent with drive from a traveling wave (Fig. 3). In this animal, at frequencies near BF the motion amplitudes at $R L_{2}$ and $R L_{3}$ were similar, but the motion at $R L_{1}$ was $\sim 15 \mathrm{~dB}$ less (Figs. 3e-g, $4 b-d$ ). In contrast, below $20 \mathrm{kHz}$ there was very little difference in the magnitudes of the $R L$ gains, and furthermore, the magnitudes were similar in the living and dead animal (Figs. $3 d, 4 a)$. However, in the phase at low frequencies, $R L_{1}$ had the same phase for the 
living and dead animal, whereas $R L_{2}$ and $R L_{3}$ had a phase advance of more than 0.25 cycles in the living animal compared to the dead animal or to $\mathrm{RL}_{1}$ (Fig. 4e).

Removing the traveling-wave phase (by normalizing by high-level $\mathrm{BM}_{\mathrm{APJ}}$ motion) and plotting frequency on a linear scale allows the phase differences (and thus group delays) of $\mathrm{RL}_{1-3}$ to be seen more easily (Fig. 4). Near $\mathrm{BF}$ and down to $30 \mathrm{kHz}$, all three $R L$ rows have phase patterns in which lower levels show a greater phase advance than higher levels (Fig. $4 \mathrm{f}-\mathrm{h}$; lower levels are thinner and have lighter colors). Above BF, this pattern reverses so that the phase delay is greater at lower levels. For all three $R L$ rows, the group delays (the negative slopes of the phase-versus-frequency functions in Fig. $4 f-h$ ) become smaller as the sound level increases (Fig. $4 f-h$ ), which is consistent with the $R L$ tuning becoming wider at higher sound levels. Interestingly, at each $R L$ row the phase-versus-frequency curves from different sound levels cross at a frequency that is slightly lower than BF (like the pattern reported for BM motion; Robles and Ruggero, 2001). The phase-crossing frequency is similar in $R L_{2}$ and $R L_{3}$, but slightly lower in frequency for $R L_{1}$ (Fig. $4 f-h$ ). Another interesting feature of the data in Figure 4 is that at high levels the $R L$ gain relative to the high-level BM $B_{\text {APJ }}$ gain peaks at a frequency that is above the BFs of the BM and RL (arrowheads versus dashed lines in Fig. 4). We will return to this in the Discussion.

The $\mathrm{RL}$ gain relative to the high-level $\mathrm{BM}_{\mathrm{APJ}}$ gain, compared across animals, is shown in Figure 5. Each horizontal-axis position shows summary statistics as box plots and individual data points as symbols from each animal, in the same animal order in all panels (and in later summary figures). From left to right, each column summarizes data from a different frequency, with the magnitudes shown in the top row and phases shown in the bottom row. The results in all columns were measured using the highest stimulus level common to measurements for all of the structures in any given animal, except for those in the third column (BF), which were measured using the lowest level available. At a representative low frequency $(10 \mathrm{kHz})$, all but one animal has $R L$ gains within $10 \mathrm{~dB}$ of the high-level $B M_{A P J}$ gain, and most $R L_{3}$ gains are higher than the $R L_{1}$ gains (Fig. 5a). All of the $R L_{2}$ and $R L_{3}$ phases are advanced relative to $B M_{A P J}$ by close to 0.25 cycles, but 7 of $9 \mathrm{RL}_{1}$ phases are close to the $\mathrm{BM}_{\mathrm{APJ}}$ phase (Fig. $5 \mathrm{e}$ ). At $30 \mathrm{kHz}$ (Fig. $5 \mathrm{~b}, \mathrm{f}$ ), which is close to 0.5 octaves below the BFs, most $R L$ gains are within $5 \mathrm{~dB}$ of the high-level $B_{A P J}$ gain, and the phases are in a narrow range between 0 and 0.25 cycles of the $B M_{\text {APJ }}$ phase, with all of the $R L_{1}$ phases less than the $R L_{3}$ phases (Fig. $5 b, f$ ). At BF (Fig. 5c, g) there are a wide range of gains across animals, but in all cases the gain of $R L_{3}$ is significantly greater than that of $R L 1$, by $10 \pm 1 \mathrm{~dB}(\mathrm{p}<0.001$, Fig. $5 \mathrm{c})$. At BF, the $R L_{1-3}$ phases are mostly within 0.25 cycles of the $B M_{\text {APJ }}$ phase, and in each animal (except one), the $R L_{1}$ and $R L_{3}$ phases are close. At the above-BF frequency, measurements of $R L$ motion relative to $B M_{A P J}$ motion (which were usually done at the highest frequency for which reliable measurements were available in the high-level $B M_{A P J}$ gain used for normalization), the $R L$ gains are consistently greater than the $B M_{A P J}$ gain and in almost all cases exhibit a phase lag compared to the BMAPJ phase (Fig. 5d, h).

\section{Motion of the three OHC rows at their junctions with the Deiters' cells (OHC-DC- junction $_{1-3}$ )}


The motions in one animal across the bottoms of the three rows of $\mathrm{OHCs}$ at their junctions with the Deiters' cells $\left(\mathrm{OHC}^{-\mathrm{DC}}\right.$ junction $\left._{1-3}\right)$ are shown in Figure 6. The OHCDC-junction gains (the displacement divided by the sound pressure) are shown on the left with a log-scaled frequency axis, and the OHC-DC-junction gains with the travelingwave drive removed (through normalization by the high-level $B_{\text {APJ }}$ gain) are shown on the right with a linear frequency axis. The gains and phases at selected frequencies are shown for all animals in Figure 7. The OHC-DC-junction data vary relatively little across animals, and the observations for the example animal (G637) generally hold across all animals (Fig. 7).

In the example animal, there is little difference in the gains of the three OHC-DCjunction rows at any frequency or level (Fig. 6a, b). At frequencies near BF, all three OHC-DC-junction rows have compressive growth and are similar in gain (Fig. 6). Near $\mathrm{BF}$, the three OHC-DC-junction rows have broad peaks at low sound levels, but at higher levels the amplitude decreases as the frequency increases, and above BF it tends to decrease (Fig. 6a). At frequencies near BF and at low sound levels, the OHC$D C$-junction gain is greater than the high-level $B_{A P J}$ gain, but at high sound levels the OHC-DC-junction gain is less than the high-level BMAPJ gain (values below zero $\mathrm{dB}$ in Fig. 6b). At frequencies just below BF (e.g., $40 \mathrm{kHz}$ ), the gain of the OHC-DC-junction motion at the highest stimulus level is actually less than in the dead animal (Fig. 6b), which implies that the active motion was partially cancelling the passive motion. A similar pattern is seen in the other animals (Supplementary Information Figures 6B, 7B).

At low frequencies (an octave or more below BF), the three OHC-DC-junction rows show linear growth at the levels tested, and considerable gain $(\sim 15 \mathrm{~dB})$ relative to the OHC-DC-junction gain in the dead animal (light color lines in Fig. 6a) and relative to the high-level $\mathrm{BM}_{\mathrm{APJ}}$ gain (Fig. 6b). Above BF, as the frequency increases, the OHC-DCjunction gain decreases relatively little (Fig. 6a), but the BMAPJ gain decreases faster so that above $\mathrm{BF}$ the OHC-DC-junction gain is greater than the high-level $\mathrm{BM}_{\mathrm{APJ}}$ gain (above BF the lines go up in Fig. 6b).

The phases of the OHC-DC-junction gains are similar across the three rows at mid frequencies, but the phases deviate from one other at high and low frequencies (Fig. 6c, d). At mid frequencies the OHC-DC-junction phases lag behind the high-level BMAPJ phase and the OHC-DC-junction phase of the dead animal by $\sim 0.25$ cycles (Fig. 6d). At the lowest frequencies, the OHC-DC-junction phase lags approach zero (Fig. 6d). Near the $\mathrm{BM}_{\mathrm{APJ}} \mathrm{BF}$, the OHC-DC-junction 3 phase lags behind the high-level BMAPJ phase by $\sim 0.25$ cycles, with rows 1 and 2 lagging more.

\section{Motion along the basilar membrane}

The gains and phases in the example animal at three points along the width of the $B M$, i.e., in the arcuate zone $\left(B_{A Z}\right)$, at $B M_{A P J}$, and in the pectinate zone $\left(B M_{P Z}\right)$, are shown in Figure 8. The locations of $B_{A Z}, B_{A P J}$, and $B M_{P Z}$ are shown in the inset of Figure 8a. The gains and phases at selected frequencies are shown for all animals in Figure 9.

As expected from previous work, the largest BM gain is at the arcuate-pectinate junction, and the phase versus frequency of the BM gain exhibits a phase delay that increases as frequency increases, consistent with excitation by a traveling wave. Near 
BF the BM gain grows compressively, and below BF the growth of the BM gain is mostly linear.

\section{Discussion}

Our measurements present a different and more complex picture of the motion within the OoC than has been conveyed by previously published measurements in the gerbil. We were able to make more-detailed measurements because our OCT system has better spatial resolution than the systems used in previous papers (Ren et al., 2016; Ren and He, 2020; He et al., 2018; He and Ren, 2021; Fallah et al., 2019; 2021; Strimbu et al., 2020; Strimbu and Olson, 2021; Cooper et al., 2018). In previous publications, the OCT images had comparatively lower resolutions, and although one could identify the BM as the first region of reflectivity past the scale, other structures within the $\mathrm{OoC}$ could not be identified based on their shapes in the image. Instead, the locations of the inner and outer tunnels were identified and the locations of structures such as the $\mathrm{OHCs}$ and/or the $\mathrm{RL}$ were inferred from the locations of the tunnels (Ren and co-workers did not have images and just used distances from the BM). In contrast, our images are of sufficiently high quality to allow us to identify the $R L$ and the bottoms (base) of the OHCs (Fig. 1e) without needing to determine their positions based on an overlaid standard image or estimates of where reflectivity measurements originated from. In some cases, three reflective peaks could be seen on the $R L$ at the tops (apical ends) of the three rows of OHCs. We identified measurements at different radial locations according to the $\mathrm{OHC}$ row they were closest to, but the alignment may not have been exact. For instance, we do not know if the structures that produce the reflectivity peaks on the $\mathrm{RL}$ correspond to an $\mathrm{OHC}$ top or an adjacent $\mathrm{PhP}$ top. Despite this uncertainty, our ability to discern radial positioning along the $\mathrm{OHC}$ rows is far greater than any previous publication, and this is the first publication to definitively identify the $\mathrm{RL}$ in the gerbil basal region and to measure from it.

\section{Our data compared to previous reports}

Previous reports used a variety of optical-beam wavelengths, bandwidths, and motion-detection processing, and since the reflectivity of a structure depends on the wavelength, motion from different structures is likely to have been measured in different experiments. In addition, the motion measured depends on the viewing angle, in part because different viewing angles can change the reflectivity of a structure, possibly due to birefringent properties of collagen fibrils in cochlear structures (Kalwani et al., 2013). Further, if the OoC is not viewed perpendicular to the BM, then supposedly "transverse" measurements will also include radial and longitudinal components. For instance, Cooper et al. (2018) measured from the gerbil $20-\mathrm{kHz}$ region as viewed through the round-window membrane (RWM). To view the $20-\mathrm{kHz}$ region through the RWM, the OCT beam must be pointed tangentially toward the apex (Fig. 1C), such that the motion measured along the axial direction of the beam will be a combination of transverse and longitudinal motion. By changing the angle of their beam, Cooper et al. (2018) concluded that much of what they measured was longitudinal motion. We developed a gentle surgical technique that produces little trauma and allowed us to measure in the $40-50-k H z$ BF region. Measurements in this region allowed us to use an OCT beam 
angle that is almost perpendicular to the BM when viewed through the RWM (Fig. 1c). Thus, our measurements are dominated by the transverse vector component of motion, with little contribution from radial or longitudinal components.

Motion measurements from within the $\mathrm{OoC}$ in the gerbil base have been reported by three other groups (Ren et al., 2016; Ren and He, 2020; He et al., 2018; He and Ren, 2021; Fallah et al., 2019; 2021; Strimbu et al., 2020; Strimbu and Olson, 2021; Cooper et al., 2018). Our measurements differ from previous reports in that: (1) we measured at three transverse locations, i.e., the $\mathrm{BM}$, the $\mathrm{OHC}-\mathrm{DC}$-junction and the $\mathrm{RL}$, whereas previous measurements were only at two locations, the BM and in the "OHC region"; and (2) we measured at several locations radially across the $\mathrm{OoC}$ at points aligned with the three rows of OHCs. There are no previous systematic measurements radially across the OHCs. We first consider the measurements at different distances from the $\mathrm{BM}$; later we consider measurements at different radial locations. We, and all previous reports, found the classic pattern of BM motion: in the BF region the BM motion was amplified (relative to the dead animal) and had compressive growth. At frequencies 0.5 octaves or more below the BF, the BM response was not amplified and grew linearly with level.

In the gerbil base, we found motions within the OoC that are substantially different from the motions previously reported (Ren et al., 2016; Ren and He, 2020; He et al., 2018; He and Ren, 2021; Fallah et al., 2019; 2021; Strimbu et al., 2020; Strimbu and Olson, 2021; Cooper et al., 2018). The primary reason for this difference appears to be that we measured from different structures than previous reports and/or used different viewing angles. We measured motion at the RL and OHC-DC-junction and identified those regions from images that were clear enough that we can be confident that those are the structures that were measured (Fig. 1, Fig. 3a). The images from the other reports did not allow such definitive identification of the structures producing the measured reflections, and the measured structures were referred to loosely as the "OHC region" (Olson group's measurements), the "hot-spot" in the OHC-Deiters' cell region (Cooper et al., 2018) or as the "RL" (Ren group's measurements, although "RL" was a blind identification that the Olson group in Fallah et al., 2019, interpreted as corresponding to their "OHC region"). We will refer to the non-BM measurements from the previous reports as "OHC region" measurements. A simplification that may be fairly accurate is that the "OHC region" motions reported by others show a combination of the motions we measured at the OHC-DC-junction and RL points.

For frequencies near BF, the previously reported "OHC region" motions show compressive nonlinearity and more gain than the BM motion. We found compressive nonlinearity near $\mathrm{BF}$ in both the OHC-DC-junction and RL motions. Near BF, our RL motion looks like the reported "OHC region" motion and usually has more gain than the $B M$ motion (for $R L_{2}$ and $R L_{3}$, but not always for $R L_{1}$ at the highest level; Fig. 4). In contrast, the OHC-DC-junction motion near BF is generally less than the BM motion (compare Figs. 6a and 9c), and has a substantially different pattern versus frequency than the reported "OHC region" motions.

For frequencies more than 0.5 octaves below BF (low frequencies), the previous reports found the "OHC region" motions to be substantially more (10-20 dB) than the BM motion in the live animal, but similar to the BM motion in the dead animal, which 
shows that the "OHC region" motions received substantial amplification at low frequencies. Our low-frequency OHC-DC-junction motion is also 10-20 dB more than the BM motion in the live animal, and similar to the BM motion in the dead animal. Thus, at low frequencies our OHC-DC-junction motions are similar to previously reported "OHC region" motions. In contrast, at low frequencies our BM $B_{A P J}$-normalized RL gain is seldom very different from $0 \mathrm{~dB}$ (Figs. 4, 5a). Interestingly, the low-frequency motion of $R L_{1}$ has a phase similar to the $B M_{A P J}$ motion (Fig. 5e), but $R L_{2}$ and $R L_{3}$ have phases that are advanced by about 0.25 cycles at the lowest frequencies (Fig. 5e). Our data show that at low frequencies the $R L$ gain magnitude is similar to the BMAPJ gain magnitude (Fig. 5a), but the OHC-DC-junction motion (which is between the RL and the BM) is 10-20 dB greater (Fig. 7a)!

\section{RL motion above BF}

One interesting finding is that at frequencies above $B F$, the $R L$ gain is larger than the BM gain (Figs. 4, 5; Supplementary Information Figs. 1-3). This is due to the BM having a slightly lower BF than the $R L$, and to the BM response falling very sharply as frequency increases, starting at frequencies just above the $B F_{B M}$, whereas the $R L$ motion does not fall as sharply (Fig. 10, a versus c). Similar findings were made by Ren et al. (2016) in gerbils and Chen et al. (2011) in guinea pigs. One explanation for this is that traveling-wave cochlear amplification falls rapidly above BF, which decreases BM motion rapidly. $\mathrm{RL}$ motion rides on top of $\mathrm{BM}$ motion and also decreases, but $\mathrm{RL}$ motion above BF also receives local amplification by the OHCs, just as it does below BF. Since the $\mathrm{OHC}$ stereocilia are no longer saturated by the drive from BM motion, they can amplify $\mathrm{RL}$ motion more than at BF. This is consistent with the effects seen by applying salicylate or furosemide (Strimbu et al., 2018; 2020).

\section{Motion at different radial positions within the organ of Corti}

This is the first report of motion within the $\mathrm{OoC}$ across the three $\mathrm{OHC}$ rows, either at the top or the bottom of the $\mathrm{OHCs}$. For frequencies near $\mathrm{BF}, \mathrm{RL}_{3}$ has significantly more motion (10 $\pm 1 \mathrm{~dB}$ ) than $\mathrm{RL}_{1}$ (Fig. 5c), but at the OHC-DC-junction there is relatively little difference across the three $\mathrm{OHC}$ rows (Fig. 7c). For frequencies below BF, the RL-gain magnitudes are similar across the three rows but the phase of $R L_{1}$ is about 0.25 cycles lower than that of $\mathrm{RL}_{2}$ and $\mathrm{RL}_{3}(\mathrm{p}<0.006)$ (Fig. 5a), while for $\mathrm{OHC}-\mathrm{DC}$-junction the gain magnitudes and phases are similar across the three rows (Fig. 7a). For the $R L_{1}$ and $R L_{3}$ motions to differ significantly from one another while the $\mathrm{OHC}-\mathrm{DC}_{1}$ and $\mathrm{OHC}-\mathrm{DC}_{3}$ motions do not differ seems to imply that the $\mathrm{RL}$ mosaic comprised of $\mathrm{OHC}$ and $\mathrm{PhP}$ cuticular plates and adhesion molecules is much more flexible than the DCs connected to the OHCs at their bottom surfaces.

Two previous reports provide sparse measurements from live animals that are consistent with our seeing more motion at $R L_{3}$ than $R L_{1}$. Fallah et al. (2019) reported measurements done at two radially separated "OHC regions" and found more motion in the more-lateral location in one case, but not in the other. Dewey et al., (2021) reported one set of interpolated measurements along the top of the mouse apical region OoC and found similar motions at $R L_{1}$ and $R L_{3}$ with $5 \mathrm{~dB}$ greater motion in the middle near $\mathrm{RL}_{2}$. Also relevant are measurements in an excised gerbil middle-turn preparation that found differences in motion in the radial and longitudinal directions across the three 
$\mathrm{OHC}$ rows at the bottom of the $\mathrm{OHCs}$ with electrical stimulation (Karavitaki and Mountain, 2007).

What do the differences in the motions across $R L_{1}, R L_{2}$, and $R L_{3}$ tell us about what is happening in the cochlea? Across our animals with available measurements, the motions of $R L_{2}$ and $R L_{3}$ are similar and those of $R L_{1}$ are different (Figs. 3-5). At high frequencies $R L_{2}$ and $R L_{3}$ have higher gains than $R L_{1}$, but all have similar phases, while at low frequencies they all have similar gains but $R L_{2}$ and $R L_{3}$ have $\sim 0.25$-cycle phase advances relative to $R L_{1}$. There are two (not mutually exclusive) classes of interpretations for the motion differences: (1) the RL motions are transverse motions with little contribution from radial and/or longitudinal $R L$ motion, and (2) the differences are primarily from non-transverse motions (radial and/or longitudinal). One simple way for there to be more transverse motion at $R L_{3}$ than $R L_{1}$ is for these motions to be made up of an OoC transverse motion plus a transverse rotation of the $\mathrm{RL}$ about a fulcrum near $\mathrm{RL}_{1}$ (e.g., at the top of the pillars as suggested by Nowotny and Gummer, 2008; 2011). Our RL data might be matched if the rotation and translation were in-phase near $\mathrm{BF}$, and if the rotation had a phase advance at low frequencies. Counting against the $R L$-rotation hypothesis is its implication that the $R L_{2}$ motion should be about half-way between the $R L_{1}$ and $R L_{3}$ motions, while the $R L_{2}$ motion is instead similar to the $R L_{3}$ motion. However, there are not enough $R L_{2}$ measurements to rule out the rotation hypothesis. If $R L$ rotation is not a big factor, and the motion is all transverse, this would mean that there is significant deformation of the $R L$.

Another possibility is that the $R L_{3}$ and $R L_{2}$ motions are greater than those of $R L_{1}$ because of non-transverse motion. This might explain the differences observed at low frequencies, because a phase difference of $\sim 0.25$ cycles can come from combining motions that are occurring in two perpendicular directions (Cooper et al., 2018). Also, the motions at $\mathrm{RL}_{1}$ and $B M_{\text {APJ }}$ can be expected to be similar because these two regions are connected by the relatively stiff outer pillar cells. However, near $B F$ the $R L_{3} / R L_{1}$ ratio is about $10 \mathrm{~dB}$ or a factor of 3 . To account for this large difference in motion there would have to be almost an order-of-magnitude more non-transverse motion than transverse motion at $R L_{3}$ compared to $R L_{2}$, because viewing angle is nearly transverse and would record only a small fraction of any radial or longitudinal motion. An order of magnitude more non-transverse motion than transverse motion in $R L_{3}$, but not in $R L_{1}$, seems unlikely. This does not mean that the $R L_{2}$ and $R L_{3}$ measurements do not include any non-transverse contributions, but that non-transverse contributions are unlikely to account for the observed differences between $R L_{3}$ and $R L_{1}$. One conclusion from all of this is that to account for our measurements, it is likely that there is substantially more transverse motion of $R L_{3}$ compared to $R L_{1}$, which means that there must be substantial deformation of the RL. In the mouse, Dewey et al. (2021) reported finding a reversal of the motion along the top of the $\mathrm{OoC}$ in the region next to $\mathrm{RL}_{3}$ at the attachment of the $\mathrm{PhP}$ furthest from the pillar cells, which would be consistent with this part of the $\mathrm{RL}$ being not very stiff.

One implication of the interpretation that the increased motions of $R L_{2}$ and $R L_{3}$ compared to $R L_{1}$ are due to transverse motion, is that the OHCs produced more motion at $R L_{2}$ and $R L_{3}$ than at $R L_{1}$. This could be because all OHC rows receive the same stereocilia deflections and produce the same $\mathrm{OHC}$ force, but that $\mathrm{RL}_{1}$ motion is 
restrained by its close attachment to the pillar cells. Alternately, the OHCs of rows 2 and 3 might receive larger stereocilia deflections and therefore produce more force. This would be consistent with there being more radial motion at $R L_{2}$ and $R L_{3}$, although this radial motion might contribute little to the transverse motion that we measured. Recently it was hypothesized that this increased radial motion could originate from expansion or contraction of the outer tunnel, whose upper wall connects to the $R L$ near $R L_{3}$ via the tectal-cell extension (Cho et al., 2022). Measurements from two or more angles are needed to decompose the motion directions into vector components at $R L_{1-3}$ to test these possibilities. Another approach would be to use a finite-element model of the RL mosaic that incorporates the radial and longitudinal angles of the PhPs across the three $\mathrm{OHC}$ rows, as well as the outer-tunnel fluid space. Regardless of the underlying reason(s) for the observed motion differences, these measurements suggest that the $\mathrm{RL}$ may not move as a stiff plate hinging around the pillar-cell heads as has been assumed, but that its mosaic structure may instead bend and/or stretch. Understanding the specifics of $\mathrm{RL}$ motion is fundamental to understanding both cochlear amplification via $\mathrm{OHC}$ stimulation and sound transduction via inner-hair-cell stimulation.

\section{Do we see a motion correlate for the frequency at which cochlear amplification starts?}

The phasing of $\mathrm{OHC}$ motion to amplify $\mathrm{BM}$ motion arises from a change in the phase of $\mathrm{RL}$ motion that, as frequency is increased, begins rather abruptly at about 0.5 octaves below BF (Dong and Olson, 2013; Lee et al., 2016; Guinan, 2020). Since the Dong and Olson (2013) measurements that identified this rapid phase change were done in the gerbil base, it seemed possible that a motion correlate of this transition would become evident in our measured motions. We have looked for such a correlate but have not been able to identify any change in the motion, such as a bend in the curves, that occurs around 0.5 octaves below BF. This could be because our RL measurements are almost purely transverse and are therefore insensitive to changes in $\mathrm{RL}$ radial motion.

\section{Animal preparation}

\section{Methods}

Healthy female Mongolian gerbils, ( $N=19$, aged 5-11 weeks, weight range 41-76 g) were used. Gerbils have the advantage of being small and having been previously used in experiments on intra-cochlear pressure (Olson, 1999, 2001; Kale and Olson, 2015), and in OCT cochlear measurements (e.g., Dong et al., 2018; Cooper et al., 2018; Fallah et al., 2019; 2021; Strimbu et al., 2020; Strimbu and Olson, 2021).

To minimize hearing damage, care was taken throughout to reduce noise and vibration (Brown, 1983). A key surgical technique was opening the bulla after applying phosphoric acid gel (PAG, PULPDENT Corporation, MA, USA) to thin (decalcify) and soften the bone (Alyono et al., 2015). PAG was applied for 10 seconds and then wiped off using a micro-wipe tip. After repeating this three times, a narrow opening in the posterolateral wall of the bulla was made with fine forceps. The tympanic membrane, malleus, incus, stapes, and RWM were all kept intact. 
Surgical procedures and anesthesia protocols were described previously (Cho et al., 2022). After the in vivo measurements, an intraperitoneal injection of Fatal Plus ( $>150$ $\mathrm{mg} / \mathrm{kg}$ ) produced euthanasia. Within 5-10 minutes after the injection, the heart typically stopped and the animal stopped breathing. The postmortem vibration measurements were done 5 to 60 min after the animal stopped breathing and had no heartbeat. This study was approved by the Institutional Animal Care and Use Committee (IACUC) at Massachusetts Eye and Ear.

\section{Stimulus generation and acoustic system}

Signal generation and sound-pressure control used a National Instruments (NI) PXI4461 dynamic signal acquisition board mounted in an $\mathrm{NI} \mathrm{PXI-1031} \mathrm{chassis} \mathrm{with} \mathrm{an} \mathrm{NI}$ PXI-8196 embedded computer (NI, TX, USA). For measuring distortion product otoacoustic emissions (DPOAEs) this was controlled using the LabVIEW-based Cochlear Function Test Suite (EPL_CFTS, version 2.37-R3041; Hickman et al., 2021). For the OCT vibrometry measurements, this used custom stimulus generation and synchronous measurement software (SyncAv, version 0.42; Gottlieb et al., 2016), which generated a sequence of pure tones $(2-63 \mathrm{kHz}, \sim 0.8 \mathrm{kHz}$ linear frequency steps). The board output was amplified by a Techron Model 5507 power amplifier (AE Techron, IN, USA) which drove a Parts Express 275-010, tweeter speaker mounted in a custom-built closed-field acoustic assembly. During the experiments, ear-canal pressure was measured by a calibrated Knowles FG-23329 electret microphone and probe tube with the probe-tube opening placed 1-2 $\mathrm{mm}$ from the tympanic membrane. Initially, an in situ pressure response with a constant stimulus voltage as a function of frequency was measured. The measured microphone response was then used to vary the stimulus voltage to equalize the ear-canal pressure and produce a near flat response across frequencies (Fig. 2a). This equalization voltage curve was scaled in approximately 10 $\mathrm{dB}$ steps (or $\sim 5 \mathrm{~dB}$ steps at higher levels) to produce the range of stimulus levels measured in the experiment. The value for the stimulus sound pressure level (SPL; in $\mathrm{dB}$ ) associated with each measurement was calculated as the average measured pressure across frequencies $(0 \mathrm{~dB} S P L=20 \mu \mathrm{Pa})$. The stimuli were varied from $\sim 30$ to $\sim 90 \mathrm{~dB}$ SPL across experiments, and the actual SPLs varied $\pm 4 \mathrm{~dB}$ due to small differences in the position of the acoustic assembly in the ear canal from the initial equalization steps.

\section{Monitoring cochlear sensitivity}

Cochlear sensitivity was monitored by DPOAEs done before and after surgery, and approximately every $20 \mathrm{~min}$ during in vivo measurements using the EPL_CFTS software (Hickman et al., 2021). DPOAEs were evoked by a series of tones at frequencies $\mathrm{f} 1$ and $\mathrm{f} 2(\mathrm{f} 2 / \mathrm{f} 1=1.2)$, with $\mathrm{f} 2$ varied from 2 to $63 \mathrm{kHz}$ in 0.5 -octave steps below $30 \mathrm{kHz}$, and $2-\mathrm{kHz}$ steps above $30 \mathrm{kHz}$. The tones were presented at equal levels in separate runs at 50 or $70 \mathrm{~dB}$ SPL. Across animals, the DPOAE amplitudes mostly ranged from $\sim 15$ to $20 \mathrm{~dB} \mathrm{SPL}$ for f2 frequencies above $30 \mathrm{kHz}$. A cochlear region's sensitivity was assessed from its DPOAE with $\mathrm{f} 2$ near BF, and was deemed adequately sensitive if the DPOAE from $50 \mathrm{~dB}$ SPL primary tones was greater than 10 $\mathrm{dB} S P L$ and the noise floor was less than $3 \mathrm{~dB}$ SPL.

\section{OCT Imaging and Vibrometry}


All OCT imaging and vibrometry measurements were done using an SD-OCT system with a 900-nm center wavelength and a high-speed (up to 240-kHz) line-scan camera (GAN620C1, Thorlabs, Germany). The OCT system combined two nearinfrared superluminescent-diode light sources with center wavelengths of $847.5 \mathrm{~nm}$ and $929.6 \mathrm{~nm}$, with full-width, half-maximum (FWHM) spectral bandwidths of 63.4 and 95.8 $\mathrm{nm}$, respectively. Before performing the fast Fourier transform (FFT), the SD-OCT system multiplied the recorded interference spectrum with an apodization (Hann) window function, which caused a broadening of the axial beam profile by a factor of 2 and had an impact on the axial resolution. The penetration depth was $\sim 1.44 \mathrm{~mm}$ (in water, with a refractive index of 1.33). The axial resolution was $\sim 2.23 \mu \mathrm{m}$ (in water) and the lateral resolution was $\sim 8 \mu \mathrm{m}$, using a $36-\mathrm{mm}, 0.055-\mathrm{NA}, 2 \times$ objective lens (OCTLK3-BB, Thorlabs, Germany).

The OCT measurements were done with custom LabVIEW (NI, TX, USA)-based VibOCT software (version 2.1.4), built using the Thorlabs SpectralRadar software development kit (version 5.4.8). This system can provide (1) real-time video images that were used in the anatomical approach to determine the region of interest for OCT scans; (2) depth-resolved 1D A-scans (reflectivity vs. axial depth, e.g., Fig. 1d); (3) 2D cross-sectional B-scans (axial depth vs. scan range, e.g., Fig.1e) with software $x-y$ offset and scan angle; (4) 3D volumetric C-scans (reflectivity vs. axial depth with scan range over two perpendicular axes), and (5) synchronous vibrometry data acquisition measurements, at a single point or for an entire A-line (axial depth), in terms of the displacement and phase in response to tones (or other stimuli). In general, the system noise floor was $\sim 0.8 \mathrm{~nm}$ at $0.1 \mathrm{kHz}$ and decreased to below $10 \mathrm{pm}$ from $\sim 10 \mathrm{kHz}$ up to $63 \mathrm{kHz}$.

For OCT vibrometry, the data acquired by an external trigger provided by the SyncAv software and trigger pulse train was synchronized with the tone stimuli at rates of up to $240 \mathrm{kHz}$ using frequency-doubling software running on a PXI-6221 board (NI, TX, USA). Phase delay in the system was compensated for using custom-built postprocessing software written in MATLAB (R2020a; Natick, MA, USA). The performance of the OCT hardware and VibOCT software was evaluated by measuring the displacement and phase of a small piezoelectric vibrator over a wide range of frequencies and stimulus levels. The OCT displacements and phase were compared to measurements made using a calibrated laser-Doppler vibrometer (LDV; Polytec OFV501/OFV2600, Irvine, CA), and both gave comparable results.

The animal was placed on a two-stage goniometer (07-GON-503, Melles Griot, Carlsbad, CA, USA) that was positioned on top of a 3-axis micro-manipulator (OCTXYR1, Thorlabs, Germany) mounted on a vibration-isolation table. The head was oriented so that measurements could be made through the intact RWM with the viewing angle adjusted to be close to transverse with respect to the $\mathrm{OoC}$ and $\mathrm{BM}$. This viewing angle provided access to BFs in the $40-50 \mathrm{kHz}$ range (see Fig. 1c). Oriented by the real-time OCT images, we chose a region of interest (e.g., BM, OHC-DC-junction, $R L$ ) from an A-scan depth profile (Fig. 1d). We then made measurement scans (M-scans), which consist of A-scan depth profiles as functions of time that contain the vibration information. Each B-scan (for imaging) and M-scan (for vibrometry) had 8,192 samples. A second FFT was performed along the time axis of the interferometric phase data for 
the extraction of vibration displacement and phase (Gao et al., 2013; Lin et al., 2019). The vibration responses to a series of sequential tones were saved to allow further viewing and post-processing at any A-line location. With our custom software, the data could be analyze during the experiment within minutes of being acquired.

\section{Statistics}

To determine the significance of the motion (magnitude and phase) of the each structure (i.e., $\mathrm{RL}_{1,2}, 3, \mathrm{OHC}-\mathrm{DC}$-junction j, 2, $_{3}$ ), we performed statistical analysis with multiway ( $n$-way) analysis of variance (ANOVA) for testing the effects of multiple factors using the built-in MATLAB function anovan (MATLAB R2020a; Natick, MA, USA). The analysis indicates that the different locations were statistically independent $(p<0.05$ criterion). The statistical results are shown in Fig. $5(\mathrm{RL})$ and Fig. 7 (OHC-DC-junction).

\section{References}

Aijaz S, Balda MS, Matter K. 2006. Tight junctions: molecular architecture and function. Int Rev Cytol 248:261-298.

Alyono JC, Corrales CE, Huth ME, Blevins NH, Ricci AJ. 2015. Development and characterization of chemical cochleostomy in the Guinea pig. Otolaryngology--head and neck surgery : official journal of American Academy of Otolaryngology-Head and Neck Surgery 152:1113-1118.

Brown MC, Smith DI, Nuttall AL. 1983. Anesthesia and surgical trauma: their influence on the guinea pig compound action potential. Hearing Res. 10:345-358.

Chen F, Zha D, Fridberger A, Zheng J, Choudhury N, Jacques SL, Wang RK, Shi X, Nuttall AL. 2011. A differentially amplified motion in the ear for near-threshold sound detection. Nat Neurosci 14:770-774.

Cho NH, Wang H, Puria S. 2022. Cochlear Fluid Spaces and Structures of the Gerbil High-Frequency Region Measured Using Optical Coherence Tomography (OCT). J Assoc Res Otolaryngol. (in press)

Cooper N, Van der Heijden M. 2018. Spatial Profiles of sound-evoked vibration in the gerbil cochlea. Pages 080001 in Bergevin C, Puria S, eds. To the ear and back again: Advances in auditory biophysics. Proc. 13th Mechanics of Hearing Workshop, vol. 1965. Melvile, NY: AIP Conference Proceedings.

Cooper NP, Vavakou A, van der Heijden M. 2018. Vibration hotspots reveal longitudinal funneling of sound-evoked motion in the mammalian cochlea. Nature communications 9:3054.

Dallos PJ, Popper AN, Fay RR. 1996. The Cochlea. Springer-Verlag.

Dong W, Olson ES. 2013. Detection of cochlear amplification and its activation. Biophys J 105:1067-1078.

Dong W, Olson ES. 2016. Two-Tone Suppression of Simultaneous Electrical and Mechanical Responses in the Cochlea. Biophysical journal 111:1805-1815. 
Dewey JB, Altoe A, Shera CA, Applegate BE, Oghalai JS. 2021. Cochlear outer hair cell electromotility enhances organ of Corti motion on a cycle-by-cycle basis at high frequencies in vivo. Proc Natl Acad Sci U S A 118.

Du TT, et al. 2019. LMO7 deficiency reveals the significance of the cuticular plate for hearing function. Nature communications 10:1117.

Fallah E, Strimbu CE, Olson ES. 2019. Nonlinearity and amplification in cochlear responses to single and multi-tone stimuli. Hearing research 377:271-281.

Fallah E, Strimbu CE, Olson ES. 2021. Nonlinearity of intracochlear motion and local cochlear microphonic: Comparison between guinea pig and gerbil. Hear Res 405:108234.

Gao SS, Raphael PD, Wang R, Park J, Xia A, Applegate BE, Oghalai JS. 2013. In vivo vibrometry inside the apex of the mouse cochlea using spectral domain optical coherence tomography. Biomed Opt Express 4:230-240.

Gottlieb, P. K., Li, X., Monfared, A., Blevins, N., and Puria, S. (2016). "First results of a novel adjustable-length ossicular reconstruction prosthesis in temporal bones," Laryngoscope 126, 2559-2564.

Guinan JJ, Jr., Salt A, Cheatham MA. 2012. Progress in cochlear physiology after Bekesy. Hear Res 293:12-20.

Guinan JJ, Jr. 2020. The interplay of organ-of-Corti vibrational modes, not tectorialmembrane resonance, sets outer-hair-cell stereocilia phase to produce cochlear amplification. Hear Res 395:108040.

He W, Kemp D, Ren T. 2018. Timing of the reticular lamina and basilar membrane vibration in living gerbil cochleae. Elife 7.

He W, Ren T. 2021. The origin of mechanical harmonic distortion within the organ of Corti in living gerbil cochleae. Commun Biol 4:1008.

Hickman, T. T., Hashimoto, K., Liberman, L. D., and Liberman, M. C. (2021). "Cochlear Synaptic Degeneration and Regeneration After Noise: Effects of Age and Neuronal Subgroup," Frontiers in Cellular Neuroscience 15.

Kale SS, Olson ES. 2015. Intracochlear Scala Media Pressure Measurement: Implications for Models of Cochlear Mechanics. Biophys J 109:2678-2688.

Karavitaki KD, Mountain DC. 2007. Imaging electrically evoked micromechanical motion within the organ of Corti of the excised gerbil cochlea. Biophys J 92:3294-3316.

Kalwani NM, Ong CA, Lysaght AC, Haward SJ, McKinley GH, Stankovic KM. 2013. Quantitative polarized light microscopy of unstained mammalian cochlear sections. Journal of biomedical optics 18:26021.

Lee HY, Raphael PD, Park J, Ellerbee AK, Applegate BE, Oghalai JS. 2015. Noninvasive in vivo imaging reveals differences between tectorial membrane and basilar membrane traveling waves in the mouse cochlea. Proc Natl Acad Sci U S A 112:3128-3133. 
Lee HY, Raphael PD, Xia A, Kim J, Grillet N, Applegate BE, Ellerbee Bowden AK, Oghalai JS (2016). Two-Dimensional Cochlear Micromechanics Measured In Vivo Demonstrate Radial Tuning within the Mouse Organ of Corti. J Neurosci. 36, 816073.

Lin NC, Fallah E, Strimbu CE, Hendon CP, Olson ES. 2019. Scanning optical coherence tomography probe for in vivo imaging and displacement measurements in the cochlea. Biomedical optics express 10:1032-1043.

Nowotny M, Gummer AW. 2006. Nanomechanics of the subtectorial space caused by electromechanics of cochlear outer hair cells. Proc Natl Acad Sci U S A 103:21202125.

Nowotny M, Gummer AW. 2011. Vibration responses of the organ of Corti and the tectorial membrane to electrical stimulation. J Acoust Soc Am 130:3852-3872.

Nunes FD, Lopez LN, Lin HW, Davies C, Azevedo RB, Gow A, Kachar B. 2006. Distinct subdomain organization and molecular composition of a tight junction with adherens junction features. J Cell Sci 119:4819-4827.

Olson ES. 1999. Direct measurement of intra-cochlear pressure waves. Nature 402:526-529.

Olson ES. 2001. Intracochlear pressure measurements related to cochlear tuning. $J$ Acoust Soc Am 110:349-367.

Ramamoorthy S, Zha D, Chen F, Jacques SL, Wang R, Choudhury N, Nuttall AL, Fridberger A. 2014. Filtering of Acoustic Signals within the Hearing Organ. J Neurosci 34:9051-9058.

Ren T, He W, Kemp D (2016) Reticular lamina and basilar membrane vibrations in living mouse cochleae. Proceedings of the National Academy of Sciences of the United States of America 113:9910-9915.

Ren, T., He, W., 2020. Two-tone distortion in reticular lamina vibration of the living cochlea. Commun Biol. 3, 35.

Robles L, Ruggero MA. 2001. Mechanics of the mammalian cochlea. Physiological Reviews 81:1305-1352.

Soons JA, Ricci AJ, Steele CR, Puria S. 2015. Cytoarchitecture of the mouse organ of corti from base to apex, determined using in situ two-photon imaging. J Assoc Res Otolaryngol 16:47-66.

Strimbu CE, Olson ES. 2021. Salicylate-induced changes in organ of Corti vibrations. Hear Res:108389.

Strimbu CE, Wang Y, Olson ES. 2020. Manipulation of the Endocochlear Potential Reveals Two Distinct Types of Cochlear Nonlinearity. Biophys J 119:2087-2101.

Van der Heijden M, Cooper NP. 2018. Wave propagation in the mammalian cochlea. Pages 080002 in Bergevin C, Puria S, eds. To the ear and back again: Advances in auditory biophysics. Proc. 13th Mechanics of Hearing Workshop, vol. 1965. Melvile, NY: AIP Conference Proceedings. 
Zha D, Chen F, Fridberger A, Choudhury N, Nuttall AL. 2011. Acoustically Evoked different vibration pattern across the width of the cochlea partition. Pages 434-437 in Shera CA, Olson ES, eds. What Fire is in Mine Ears: Progress in Auditory Biomechanics.

\section{Acknowledgements}

We thank John J. Guinan, Jr., for extensive discussion and help in writing the manuscript; Kevin N. O'Connor for the data analysis scripts (SyncAv Toolbox) and editing assistance; Anbuselvan Dharmarajan and Gabriel Alberts for animal surgery; Michael E. Ravicz for technical support; and Andrew A. Tubelli for the OoC-structure drawings (Fig. 1C, g). This work was supported in part by Grant R01 DC07910 from the National Institute on Deafness and Other Communication Disorders (NIDCD) of the $\mathrm{NIH}$, and the Amelia Peabody Charitable Fund.

\section{Author contributions}

N.H.C. and S.P conceived of and designed the project. N.H.C developed the VibOCT software used for these measurements. Both conducted experiments, plotted, and analyzed data. S.P. and N.H.C wrote and edited the manuscript, and S.P. supervised the project.

\section{Data availability}

All data needed to evaluate the conclusions in the paper are present in the paper. Additional data related to this paper may be requested from the authors.

\section{Competing Interests}

The authors declare that they have no competing interests.

\section{Additional Information}

Supplementary Information is available. 
bioRxiv preprint doi: https://doi.org/10.1101/2022.03.01.482580; this version posted March 4, 2022. The copyright holder for this preprint (which was not certified by peer review) is the author/funder, who has granted bioRxiv a license to display the preprint in perpetuity. It is made available under aCC-BY-NC-ND 4.0 International license.
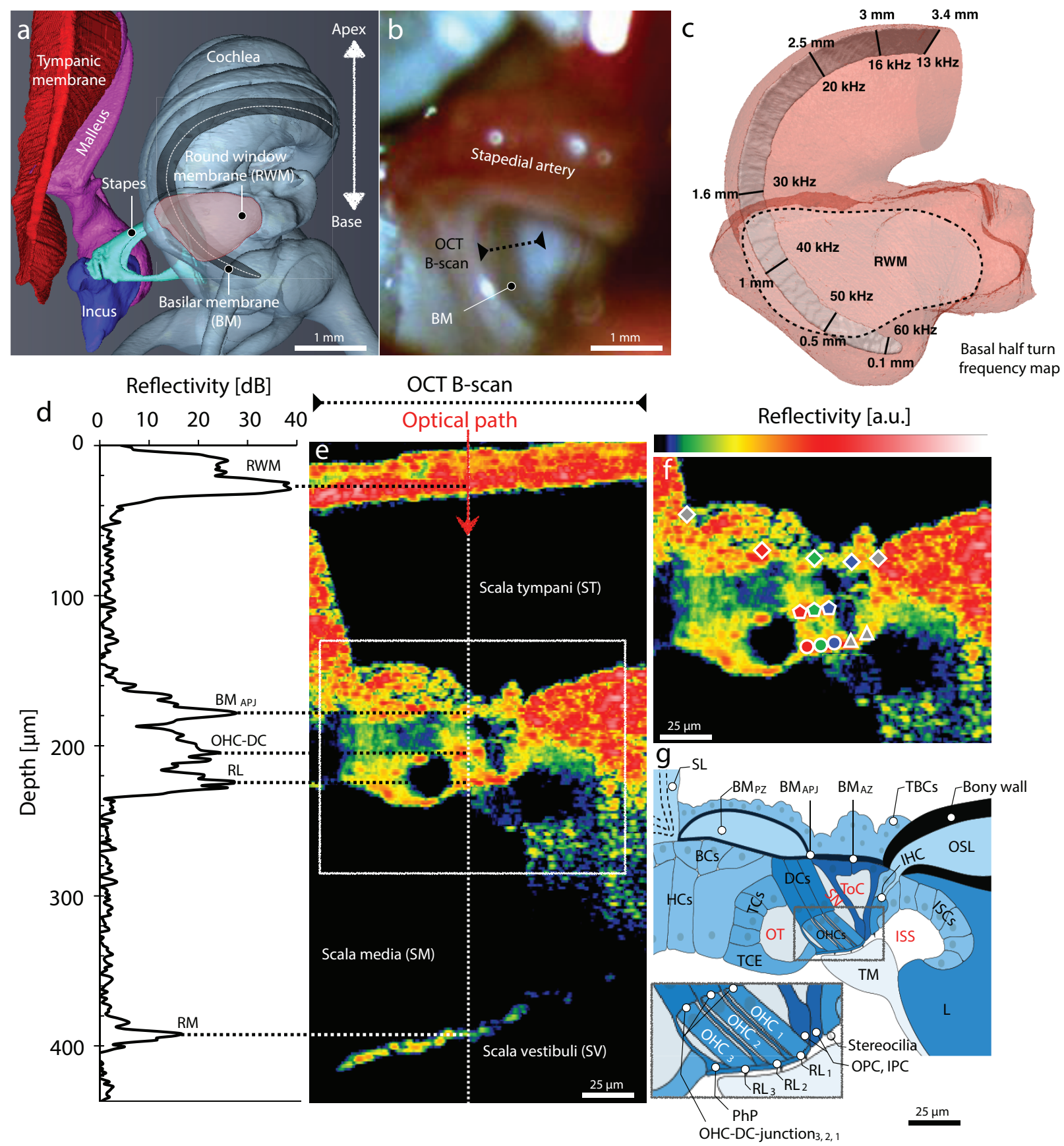

Fig. 1 The anatomy of the gerbil ear and in vivo cochlea imaging. a A micro-computed-tomography ( $\mu \mathrm{CT})$-based 3D reconstruction shows the main structures of the gerbil middle ear (i.e., tympanic membrane, malleus, incus, and stapes), and the cochlea (base to apex) with the round-window membrane (RWM; pink region) and internal basilar membrane (BM; dark-gray region) indicated. b A photograph (specimen G504) shows the RWM region through which 2D "B-scan" cross sections of the BM in the basal "hook region" of the cochlea can be imaged using optical coherence tomography (OCT; black dotted line). c The frequency map of the BM "basal half turn" (from panel a) is shown as a function of distance from the basal tip. $\mathbf{d}$ An example of the depth profile (backscattered-light reflectivity) of a single 1D "A-scan" (white dotted line in e) shows several peaks corresponding to: the RWM; the junction (BMAPJ) of the BM arcuate zone $\left(\mathrm{BM} \mathrm{Az}_{\mathrm{A}}\right.$ ) and pectinate zone (BMPz); the junction (OHC-DC) of an outer hair cell $(\mathrm{OHC})$ and Deiters' cell (DC); the reticular lamina (RL); and Reissner's membrane (RM). e An in vivo OCT B-scan image (G612), as measured through the RWM. f Enlarged view of $\mathbf{e}$ detailing the organ of Corti $(\mathrm{O} \circ \mathrm{C})$ structure and marking the following OCT-vibrometry measurement points (left to right and top to bottom): outer $B M$ edge, $B M_{P Z}, B M_{A P J}, B_{A Z}$, inner $B M$ edge 
bioRxiv preprint doi: https://doi.org/10.1101/2022.03.01.482580; this version posted March 4, 2022. The copyright holder for this preprint (which was not certified by peer review) is the author/funder, who has granted bioRxiv a license to display the preprint in perpetuity. It is made available under aCC-BY-NC-ND 4.0 International license.

(gray/red/green/blue/gray diamonds); OHC-DC-junction ${ }_{3,2,1}$ (red/green/blue pentagons); RL $L_{3,2,1}$ (red/green/blue circles); and outer and inner pillar cells (OPC and IPC; gray triangles). g A labeled cross-sectional drawing of a representative $\mathrm{OoC}$ structure. The inset details the three rows of OHCs where they meet the RL at their apical ends, as well as the OPC, IPC, and inner-hair-cell (IHC) stereocilia. Other abbreviations: SL: spiral ligament; TBCs: tympanic border cells; BCs: Boettcher cells; OSL: osseous spiral lamina; HCs: Hensen's cells; TCs: tectal cells; TCE: tectal-cell extension; ISCs: inner-sulcus cells; TM: tectorial membrane; L: limbus; OT: outer tunnel; SN: Space of Nuel; ToC: tunnel of Corti; ISS: inner spiral sulcus; PhP: phalangeal process. 
bioRxiv preprint doi: https://doi.org/10.1101/2022.03.01.482580; this version posted March 4, 2022. The copyright holder for this preprint (which was not certified by peer review) is the author/funder, who has granted bioRxiv a license to display the preprint in perpetuity. It is made available under aCC-BY-NC-ND 4.0 International license.
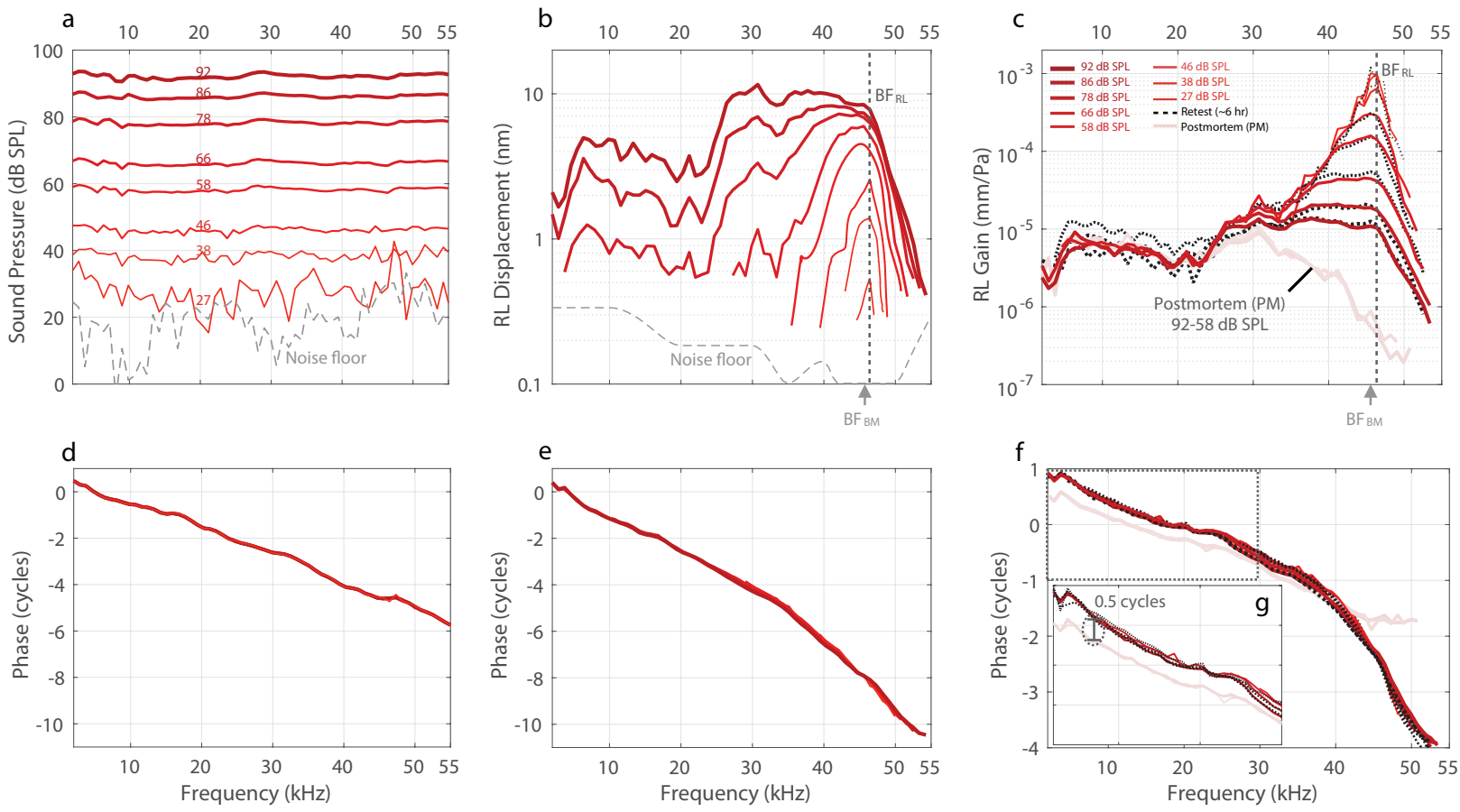

Fig. 2 In vivo $\mathrm{RL}_{3}$ vibrometry measurements (see Fig. $1 \mathrm{~g}$ inset) at different stimulus levels in the hook region of the gerbil cochlea (G637). a The ear-canal sound pressure levels of pure tones used to stimulate the specimen, ranging from 27 to $92 \mathrm{~dB}$ SPL (line thickness and darkness increase with level), as well as a noise-floor reading (gray dashed line). b RL3 displacements as functions of frequency, corresponding to the different stimulus levels in panel a. Displacement measurements were rejected at frequencies where their magnitude was less than $6 \mathrm{~dB}$ above the noise floor (gray dashed line). The best frequency $(B F)$ for the $\mathrm{RL}_{3}$ location (BF $\mathrm{RL}$ ) is $46.4 \mathrm{kHz}$ (gray dotted vertical line), and for the $\mathrm{BM}_{\mathrm{APJ}}$ location $\left(\mathrm{BF}_{\mathrm{BM}}\right.$ ) is $45.6 \mathrm{kHz}$ (gray arrow below the panel). c The in vivo (dark red) and postmortem (PM; faded red) $R L_{3}$ displacements are normalized by the stimulus sound pressure to produce the $R L$ Gain (in units of $\mathrm{mm} / \mathrm{Pa}$ ). The black dotted lines indicate repeated in vivo measurements made $\sim 6$ hours later. $\mathbf{d}-\mathbf{f}$ The respective phase responses of the sound pressure, $R L_{3}$ displacement, and $R L_{3}$ gain. $g$ An enlarged view of the $R L_{3}$ gain from the blackdotted region of panel f. $s$ 
bioRxiv preprint doi: https://doi.org/10.1101/2022.03.01.482580; this version posted March 4, 2022. The copyright holder for this preprint (which was not certified by peer review) is the author/funder, who has granted bioRxiv a license to display the preprint in perpetuity. It is made available under aCC-BY-NC-ND 4.0 International license.
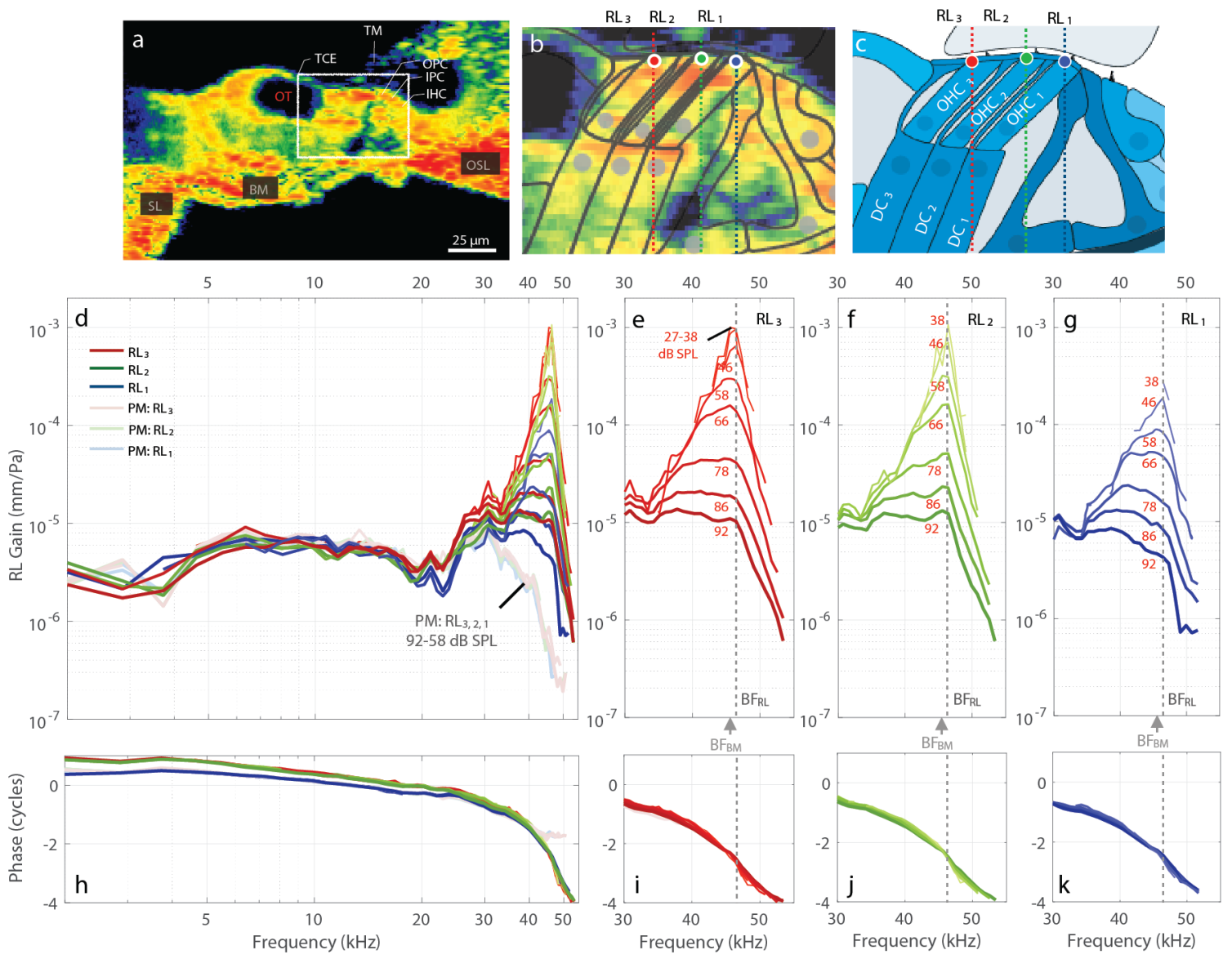

Fig. 3 The in vivo and PM RL Gains across the apical ends of the three rows of $O H C s\left(R L_{3}, R L_{2}, R L_{1}\right.$; $\left.G 637\right)$. a $A$ 2D cross-sectional OCT image of a representative in vivo gerbil OoC with labeled key structures. Note that the OoC structure is displayed upside down in comparison to Fig. 1. b An enlargement of the region in panel a within the white box, with overlaid line drawings of the cells and other structures, and details of the measurement locations across the apical ends of the three rows of $O H C s$ shown ( $R L_{3}$ : red circle; $\mathrm{RL}_{2}$ : green circle; and $\mathrm{RL}_{1}$ :blue circle). Each colored vertical line indicates the lateral position and direction of the different OCT A-scans made during the OCT vibrometry measurements. c A labeled cross-sectional drawing from the 2D OCT image in panel b. $\mathbf{d}$ In vivo (dark red/green/blue colors) and PM (faded red/green/blue colors) gains for $R L_{3}, R L_{2}$, and $R L_{1}$, respectively. $\mathbf{e}-\mathbf{g}$ The in vivo near-BF gain region for $R L_{3}, R L_{2}$, and $R L_{1}$, respectively, showing active amplification. The gains were highest at low SPLs (note that curves overlap for the 27-38 dB SPL stimuli in panel $\mathbf{e}$. The overlaid numbers in panels $\mathbf{e}-\mathbf{g}$ indicate the stimulus level for each gain response. $\mathbf{h}-\mathbf{k}$ The phase responses corresponding to panels $\mathbf{d}-\mathbf{g}$, respectively. Note that in this figure the displacements are normalized by the sound pressure to produce gains in units of $\mathrm{mm} / \mathrm{Pa}$, and the phase responses are in units of cycles. The frequency axis is on a log scale in panels $\mathbf{d}$ and $\mathbf{h}$, but on a linear scale in panels $\mathbf{e}-\mathbf{g}$ and $\mathbf{i}-$ k. 
bioRxiv preprint doi: https://doi.org/10.1101/2022.03.01.482580; this version posted March 4, 2022. The copyright holder for this preprint (which was not certified by peer review) is the author/funder, who has granted bioRxiv a license to display the preprint in perpetuity. It is made available under aCC-BY-NC-ND 4.0 International license.
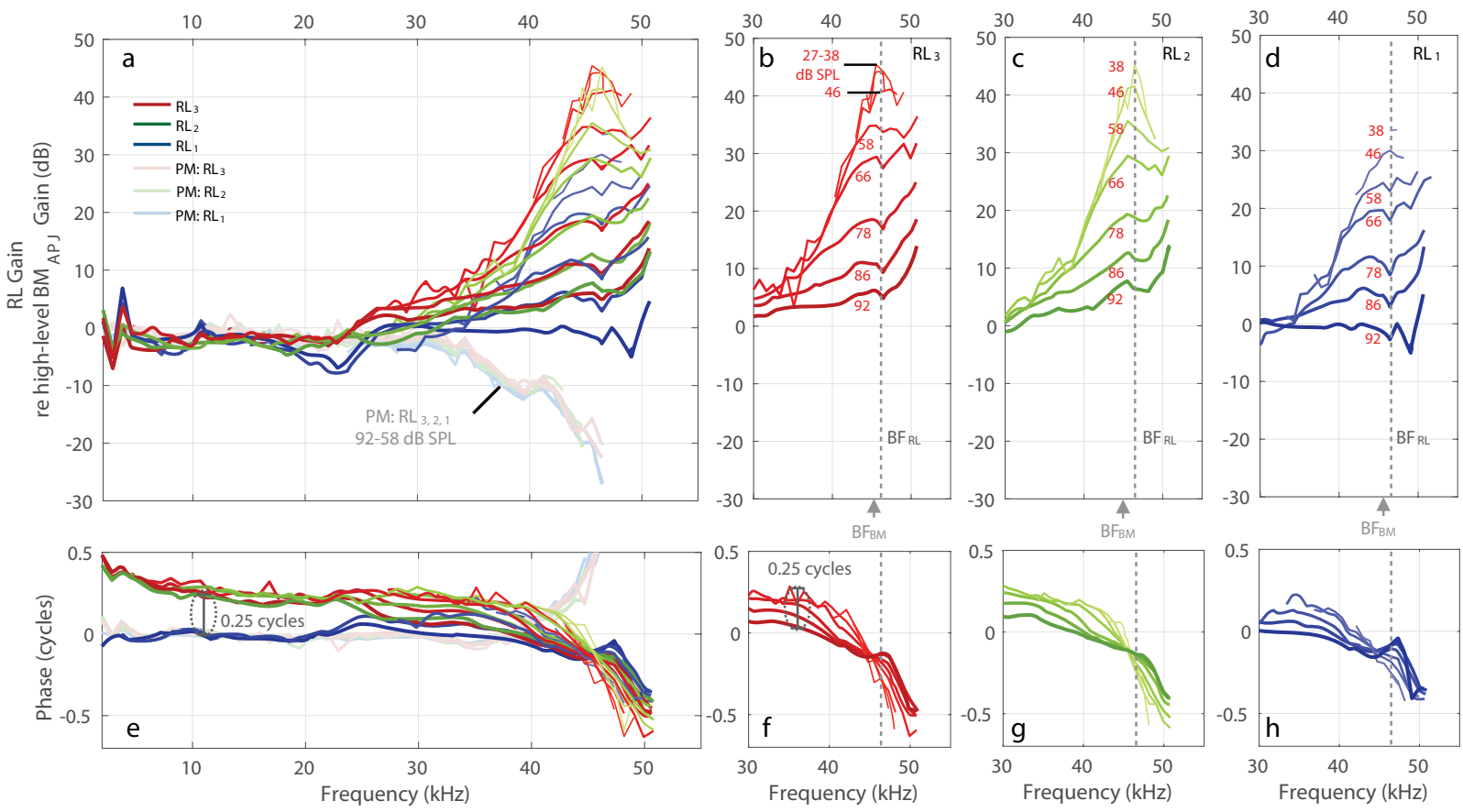

Fig. 4 The in vivo and PM RL gains, normalized by the BMAPJ gain (measured at a high stimulus level), in order to remove the effects of the cochlear traveling wave, for specimen G637. a Direct comparisons of the in vivo and PM RL 2,1 normalized gains (in $d B$ ). $\mathbf{b}-\mathbf{d}$ In vivo normalized gains in the near-BF region for $R L_{3}, R L_{2}$, and $R L_{1}$, respectively. $\mathbf{e}-$ $\mathbf{h}$ The phase responses corresponding to panels a-d, respectively. Note that the baseline high-level BMAPJ gain used for normalization was calculated as the average of ten measurements made at $92 \mathrm{~dB}$ SPL. All frequency axes in this figure are on a linear scale. 
bioRxiv preprint doi: https://doi.org/10.1101/2022.03.01.482580; this version posted March 4, 2022. The copyright holder for this preprint (which was not certified by peer review) is the author/funder, who has granted bioRxiv a license to display the preprint in perpetuity. It is made available under aCC-BY-NC-ND 4.0 International license.

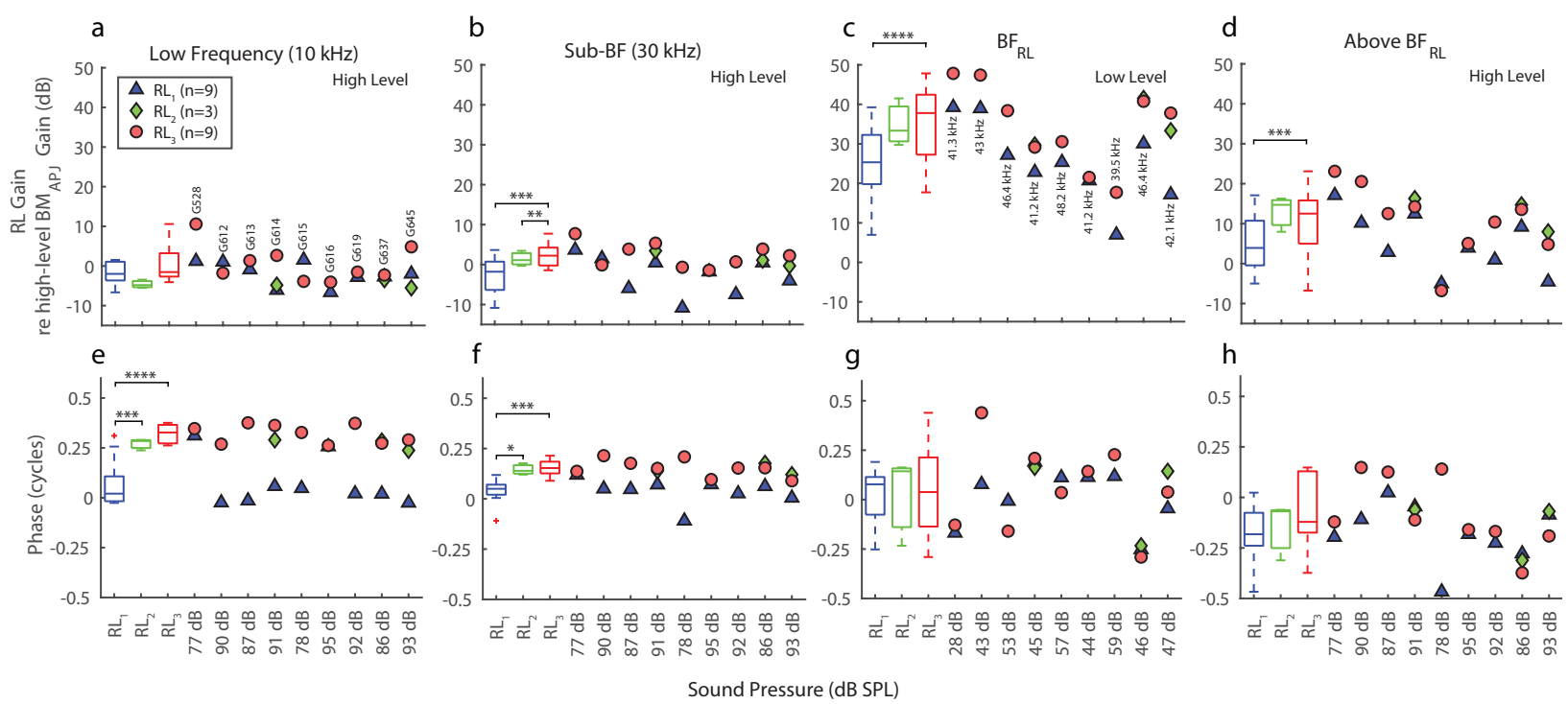

Fig. 5 Summary comparisons across animals of the in vivo normalized gains at the apical ends of the OHC rows (RL3, $2,1)$, for selected frequencies. a-d The respective normalized-gain magnitudes at a low frequency $(10 \mathrm{kHz}$, high stimulus level), near $30 \mathrm{kHz}$ (Sub-BF, high stimulus level), at BFrL (low stimulus level), and above BF (high stimulus level). The above-BFRL frequencies used in panels $\mathbf{d}$ and $\mathbf{h}$ correspond to the high-stimulus-level magnitude peak for each animal. $\mathbf{e}-\mathbf{h}$ The phase summaries corresponding to panels $\mathbf{a}-\mathbf{d}$, respectively. The individual datapoints in columns $1-2$ were averaged over a 1/3-octave width centered around 10 and $30 \mathrm{kHz}$, respectively, while those in column 4 were averaged over a 1/6-octave width centered around the selected frequency. The points shown in column 3 each represent the value at a single frequency. Note that the stimulus levels listed on the horizontal axes and BF values labeled in panel c vary across animals (labeled in panel a). The box-and-whisker plots on the left-hand side of each panel provide statistical summaries of the individual results, matched by color. The ANOVA $p$-values between categories are indicated by horizontal brackets at the top. The number of asterisks above each bracket corresponds to the following degrees of statistical significance: $p<0.05\left(^{*}\right), p<0.02\left(^{* *}\right), p<0.006\left(^{* * *}\right)$, and $p<0.001\left(^{* * *}\right)$, all of which are of greater significance than the $p_{0}=0.05$ criterion. Insignificant $p$-values are not displayed. The red ' + ' symbols indicate outliers, the boxes indicate the interquartile range (IQR) with 95\% confidence, and the horizontal line inside each box indicates the median value. The whiskers indicate the minimum and maximum of the range (excluding outliers). In some cases the $R L_{2}$ whiskers are too small to be visible. The $R L_{3,2,1}$ results for animal $G 637$ are shown in Figs. 3 and 4 . 
bioRxiv preprint doi: https://doi.org/10.1101/2022.03.01.482580; this version posted March 4, 2022. The copyright holder for this preprint (which was not certified by peer review) is the author/funder, who has granted bioRxiv a license to display the preprint in perpetuity. It is made available under aCC-BY-NC-ND 4.0 International license.
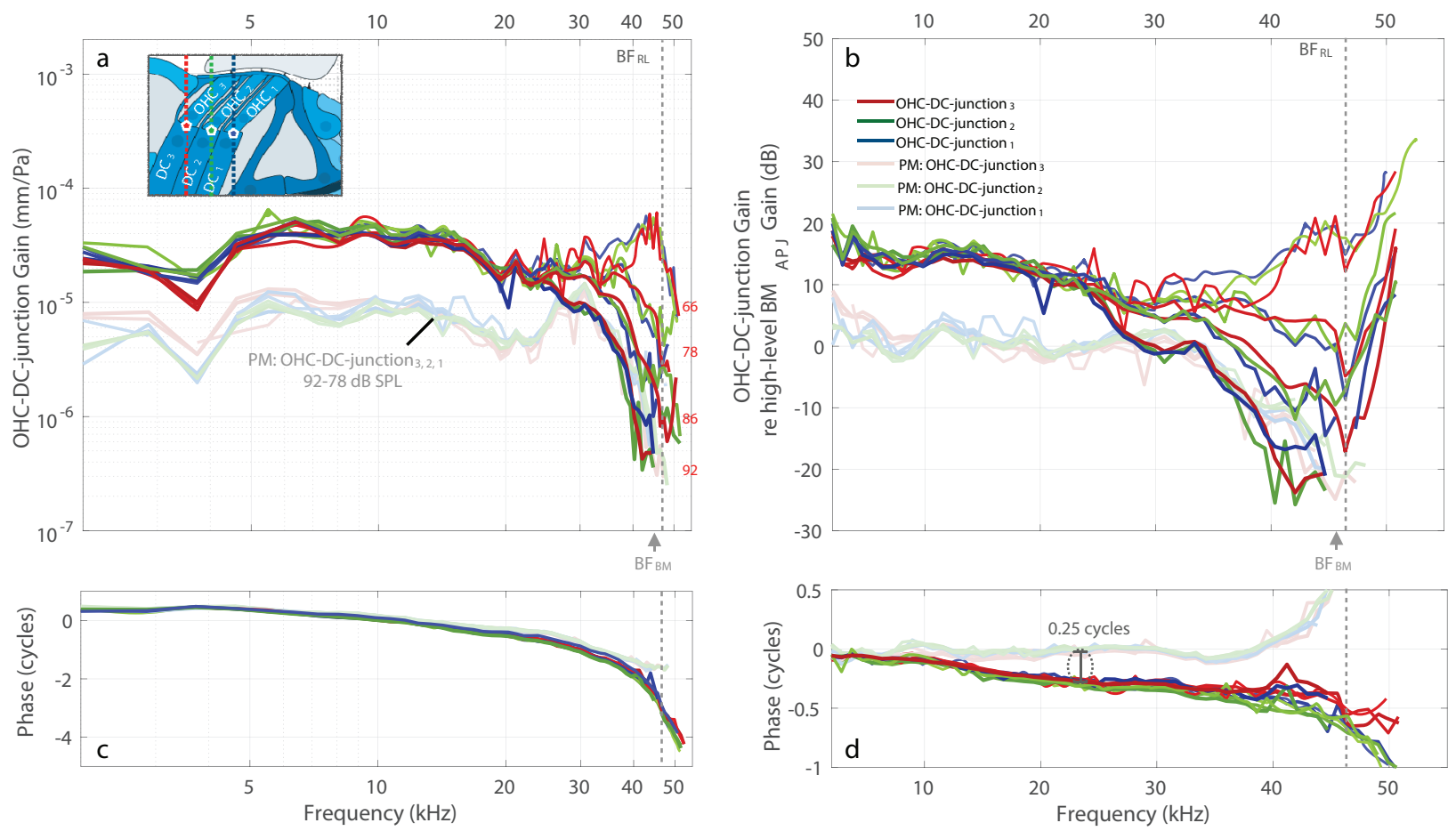

Fig. 6 Motion comparisons of the OHC-DC junctions at the basal ends of the OHCs, across the three $\mathrm{OHC}$ rows (OHCDC-junction $3,2,1$ ), for specimen G637. a In vivo (darker colors) and PM (faded colors) OHC-DC-junction $3,2,1$ gains relative to the sound pressure (in units of $\mathrm{mm} / \mathrm{Pa}$ ). $\mathbf{b}$ The gains in a normalized by the high-level (92 $\mathrm{dB} S \mathrm{SPL}$ ) BMAPJ gain (in dB). Note that the inset drawing in panel a shows the OCT-vibrometry measurement locations for OHC-DCjunction $_{3}$ (red pentagon), OHC-DC-junction 2 (green pentagon), and OHC-DC-junction 1 (blue pentagon). Each colored vertical line indicates the lateral position and direction of the different OCT A-scans acquired during the OCT vibrometry measurements. $\mathbf{c}-\mathbf{d}$ The phase responses corresponding to panels $\mathbf{a}-\mathbf{b}$, respectively. Note that the frequency axes are on a log scale in the first column and on a linear scale in the second column. 
bioRxiv preprint doi: https://doi.org/10.1101/2022.03.01.482580; this version posted March 4, 2022. The copyright holder for this preprint (which was not certified by peer review) is the author/funder, who has granted bioRxiv a license to display the preprint in perpetuity. It is made available under aCC-BY-NC-ND 4.0 International license.
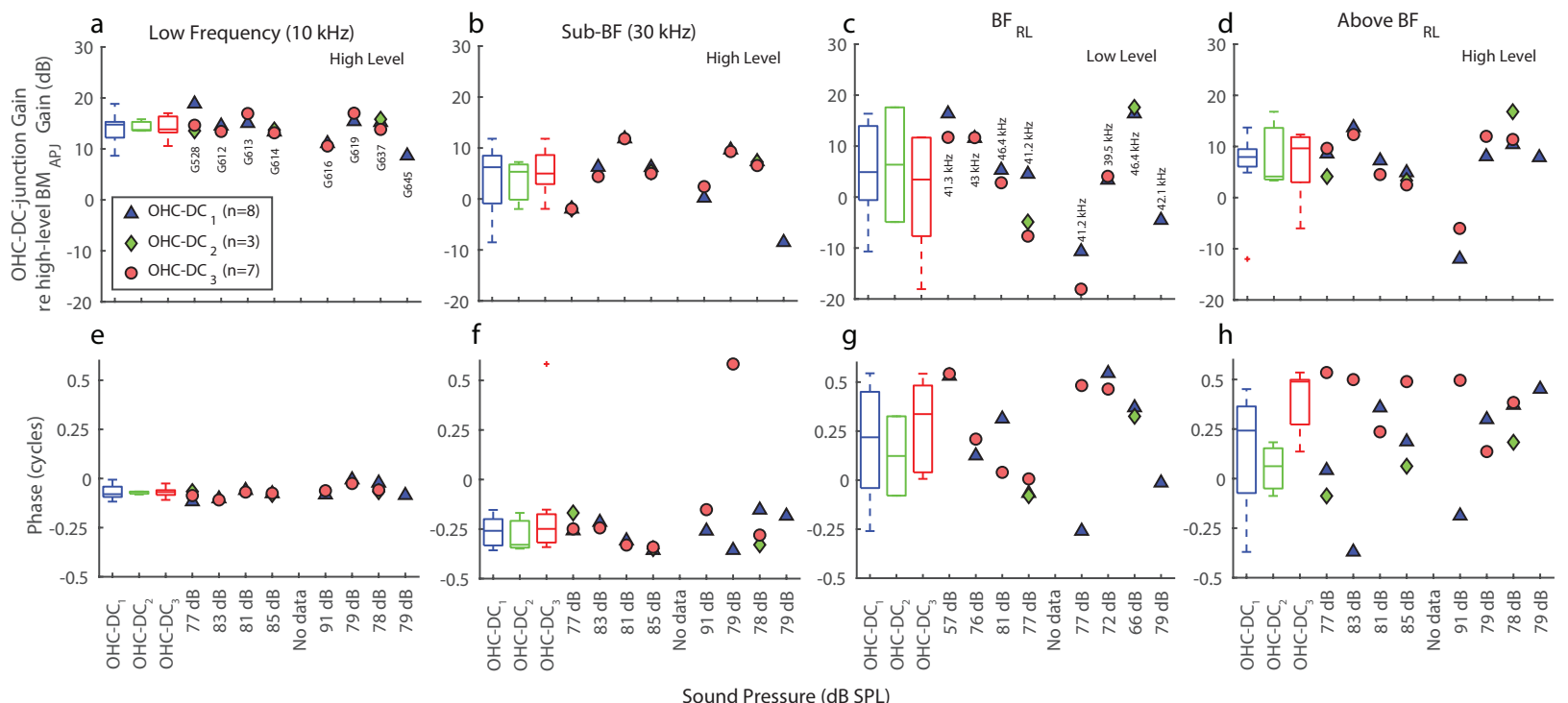

Fig. 7 Summary comparisons of the in vivo normalized OHC-DC-junction at the basal ends of the OHCs gains across animals for the three $\mathrm{OHC}$ rows $\left(\mathrm{OHC}-\mathrm{DC}_{3,2,1}\right)$. $\mathbf{a}-\mathbf{h}$ The normalized-gain magnitudes $(\mathbf{a}-\mathbf{d})$ and corresponding phases $(\mathbf{e}-\mathbf{h})$, each with respective box-and-whisker-plot summaries, using the same frequencies and methods described in Fig. 5. The ANOVA $p$-values are all insignificant in this figure. The OHC-DC-junction ${ }_{3,2,1}$ results for animal G637 are shown in Fig. 6. 
bioRxiv preprint doi: https://doi.org/10.1101/2022.03.01.482580; this version posted March 4, 2022. The copyright holder for this preprint (which was not certified by peer review) is the author/funder, who has granted bioRxiv a license to display the preprint in perpetuity. It is made available under aCC-BY-NC-ND 4.0 International license.
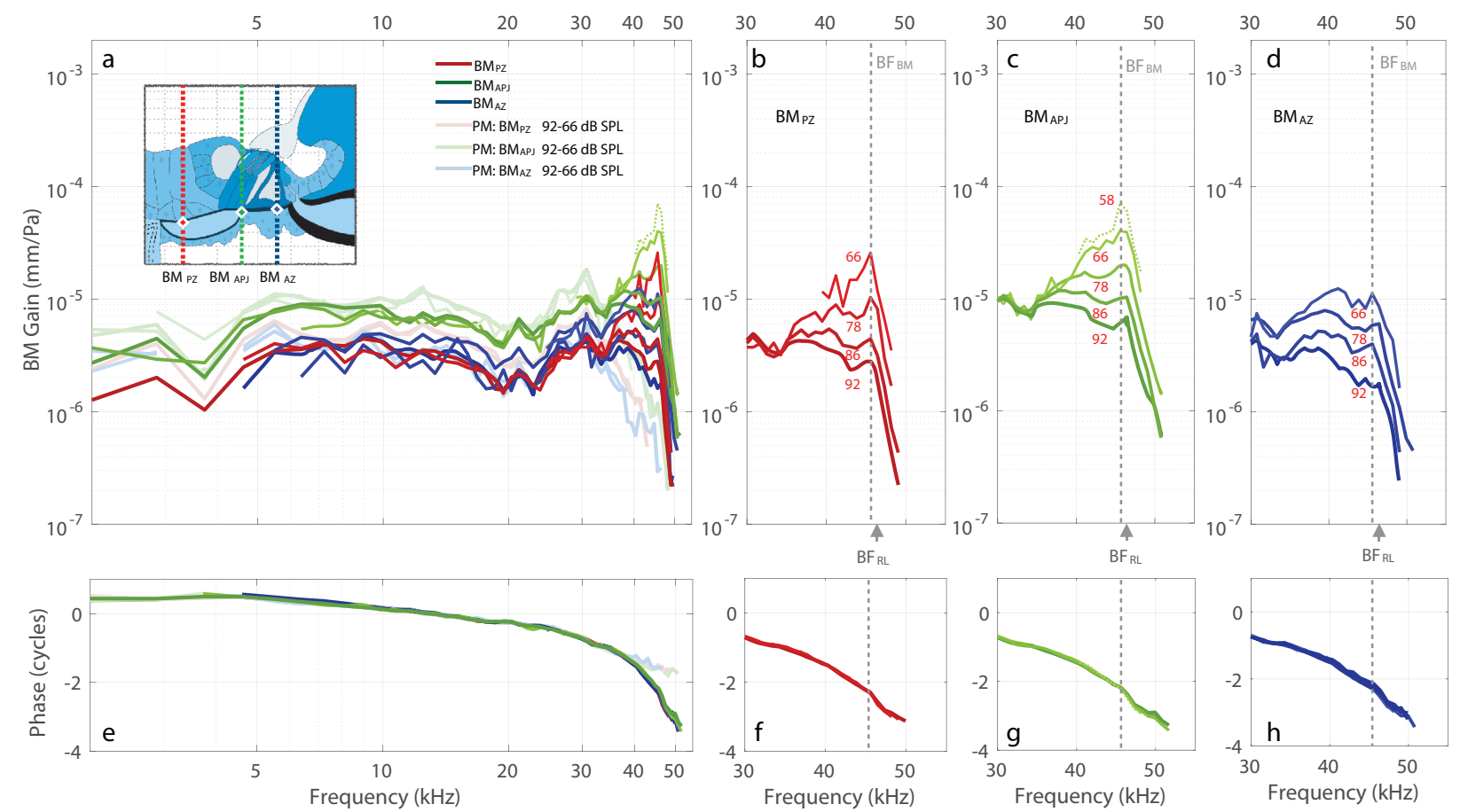

Fig. 8 In vivo and $P M$ motions across three $B M$ locations (BMPZ, BMAPJ, and $B M_{A Z}$ ), for specimen G637. a In vivo (darker colors) and PM (faded colors) BMPZ, BMAPJ, and BMAZ gains with respect to the stimulus pressure (in units of $\mathrm{mm} / \mathrm{Pa}$ ). The green dotted line indicates the lowest-level BMAPJ measurement. The inset drawing shows the measurement locations for BMPZ (red diamond) BMAPJ (green diamond), and BM $\mathrm{BZ}_{\mathrm{AZ}}$ (blue diamond). Each colored vertical line indicates the lateral position and direction of the different OCT A-scans acquired during the OCT vibrometry measurements. $\mathbf{b}-\mathbf{d}$ The respective in vivo gains of the different BM locations, showing active nonlinear amplification in the near-BF region. $\mathbf{e}-\mathbf{h}$ The respective phase responses corresponding to panels $\mathbf{a}-\mathbf{d}$. Note that the displacements are normalized by the sound pressure in all panels. The frequency axes in the first column are on a log scale, and those of the remaining columns are on a linear scale. 
bioRxiv preprint doi: https://doi.org/10.1101/2022.03.01.482580; this version posted March 4, 2022. The copyright holder for this preprint (which was not certified by peer review) is the author/funder, who has granted bioRxiv a license to display the preprint in perpetuity. It is made available under aCC-BY-NC-ND 4.0 International license.
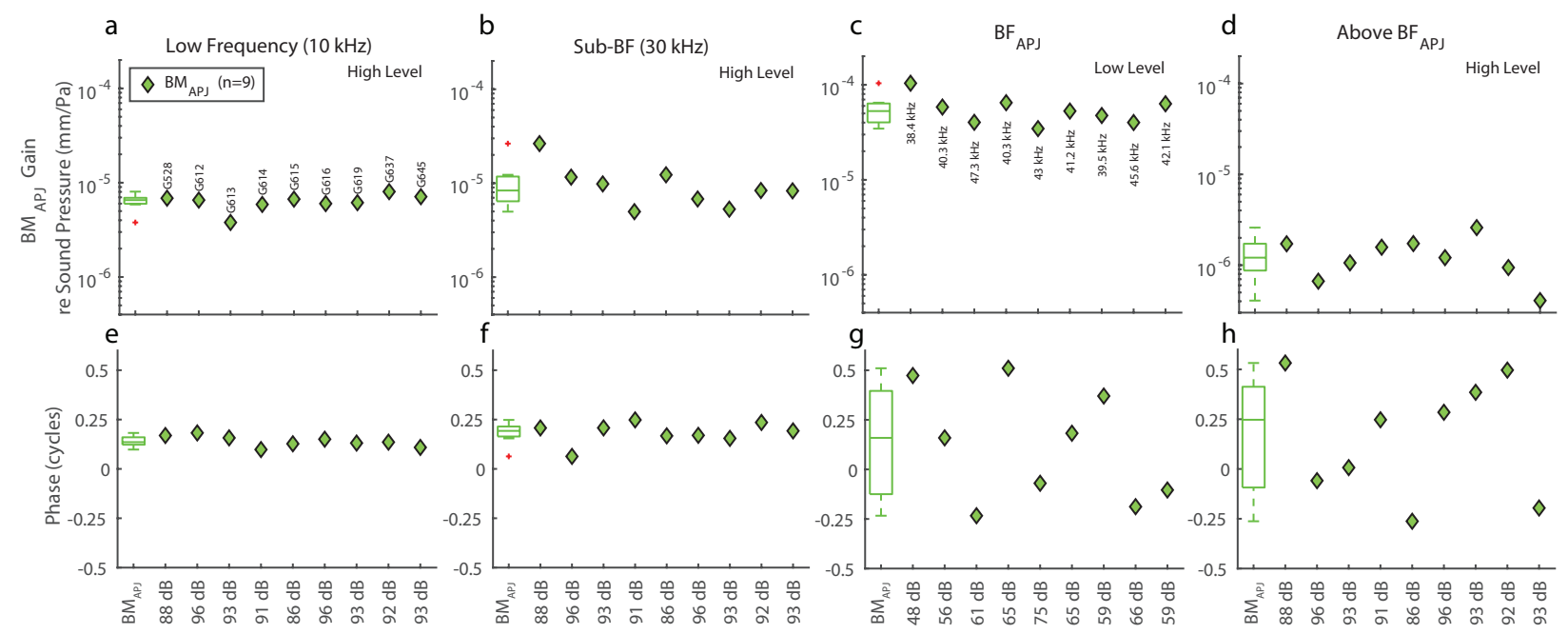

$\mathrm{h}$

$$
\text { Sound Pressure (dB SPL) }
$$

Fig. 9 Summary comparisons across animals of the in vivo BMAPJ gains with respect to the sound pressure (in units of $\mathrm{mm} / \mathrm{Pa}$ ), for selected frequencies. $\mathbf{a}-\mathbf{h}$ The gain magnitudes $(\mathbf{a}-\mathbf{d})$ and corresponding phases $(\mathbf{e}-\mathbf{h})$, each with $\mathbf{a}$ respective box-and-whisker-plot summary. The frequencies in the first two columns match those of Figs. 5 and 7, hover

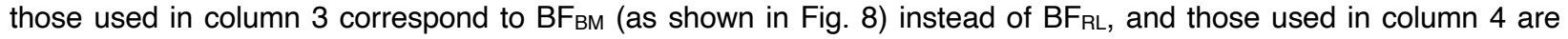
quarter-octave above the frequencies used in column 3. The BMAPJ results for animal G637 are shown in Fig. 8. 
bioRxiv preprint doi: https://doi.org/10.1101/2022.03.01.482580; this version posted March 4, 2022. The copyright holder for this preprint (which was not certified by peer review) is the author/funder, who has granted bioRxiv a license to display the preprint in perpetuity. It is made available under aCC-BY-NC-ND 4.0 International license.
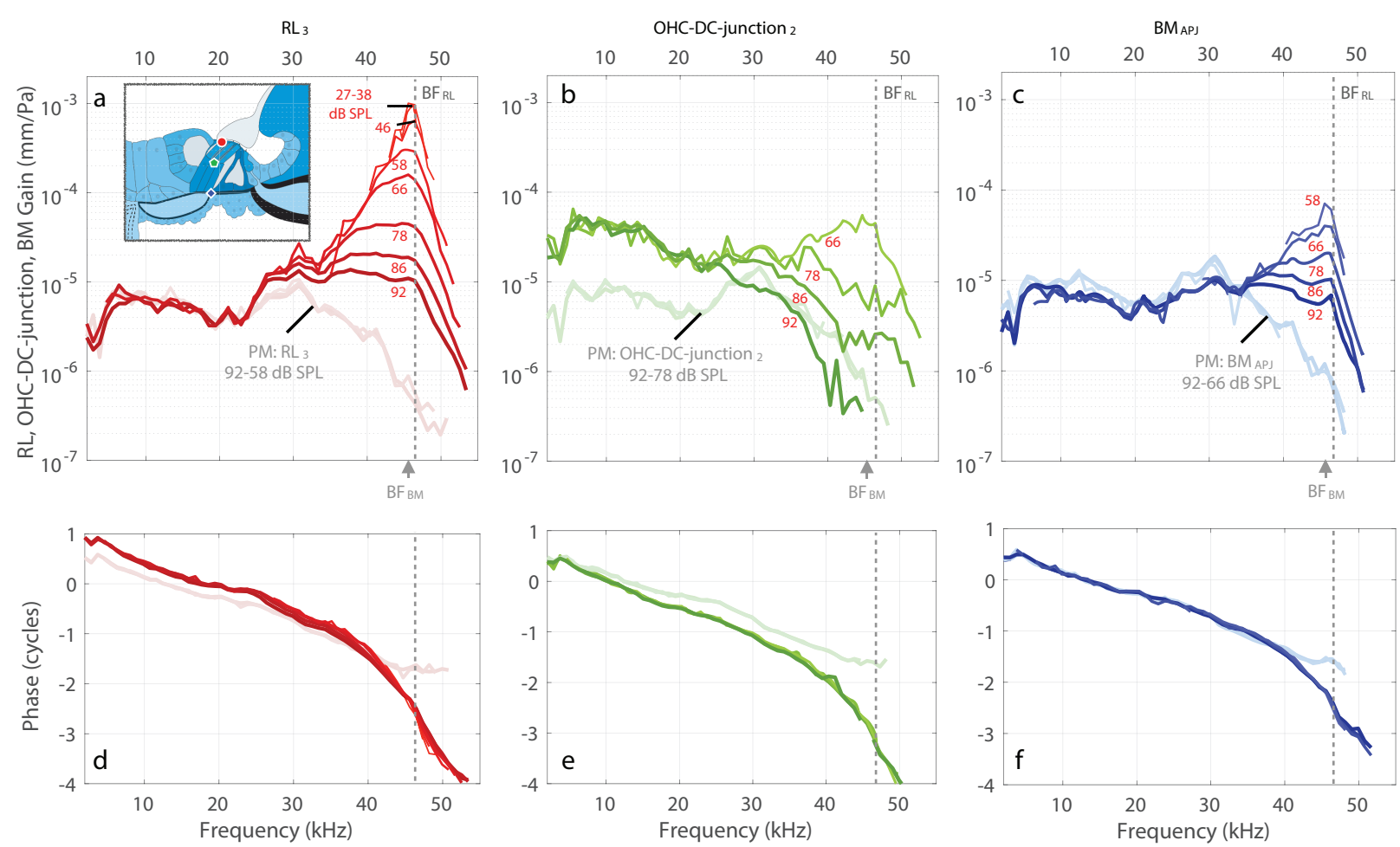

Fig. 10 In vivo (darker colors) and PM (faded colors) gain comparisons across different OoC structures along a transverse direction, for specimen G637. a-c The respective gain magnitudes of $\mathrm{RL}_{3}$ (red), OHC-DC-junction 2 (green), and BMAPJ (blue), all relative to the sound pressure (in units of $\mathrm{mm} / \mathrm{Pa}$ ). The inset drawing in panel a shows the measurement locations for $\mathrm{RL}_{3}$ (red circle), OHC-DC-junction 2 (green pentagon), and BMAPJ (blue diamond). d-f The respective phase responses corresponding to a-c. Note that the available stimulus levels vary across the structures due to different signal-to-noise ratios. 